\title{
Histopathology of the right ventricular outflow tract and the relation to hemodynamics in patients with repaired tetralogy of Fallot
}

\author{
Ujjwal Kumar Chowdhury, MCh, Diplomate NB, ${ }^{a}$ Aandrei Jha, MCh, ${ }^{a}$ Ruma Ray, MD, FRCP, \\ Mani Kalaivani, MSc (Biostat), PhD, ${ }^{\mathrm{c}}$ Suruchi Hasija, DM, ${ }^{\mathrm{d}}$ Lakshmi Kumari, MCh, ${ }^{\mathrm{a}}$ and \\ Abhinavsingh Chauhan, $\mathrm{MS}^{\mathrm{a}}$
}

\section{ABSTRACT}

Objective: To evaluate the relationship between myocardial histopathology and tissue Doppler imaging (TDI) variables of the right ventricle and postoperative peak systolic right-to-left ventricular pressure ratio (Prv/Plv) in patients undergoing intracardiac repair for tetralogy of Fallot (TOF).

Methods: Operatively resected crista supraventricularis muscle specimens from 93 patients undergoing intracardiac repair for TOF, aged 18 months to 26 years (mean, $7.02 \pm 5.35$ years) were subjected to light microscopy. TDI-derived parameters between the normal and abnormal categories of myocardium, the evolution of Prv/Plv, and its relationship to TDI-derived variables were tested using generalized linear random effects model using xtreg command.

Results: The incidence of myocyte hypertrophy, myocytolysis, and perivascular fibrosis was $89.2 \%, 83.8 \%$, and $77.4 \%$, respectively. Although tricuspid annular peak systolic excursion, peak myocardial velocity during systole ( $\left.\mathrm{s}^{\prime}\right)$, and early diastolic basal lengthening of right ventricle $\left(\mathrm{e}^{\prime}\right)$ continued to improve among patients with myocardial hypertrophy, myocytolysis, and perivascular fibrosis, there was an absence of improvement of the late diastolic relaxation of right ventricular free wall $\left(\mathrm{a}^{\prime}\right)$ in patients with perivascular fibrosis. Although there was improvement of postoperative Prv/Plv in patients with myocardial fibrosis as compared with normal histology, the values were not statistically significant ( $\beta$ [standard error] -0.07 [0.08], $P=.3$ ).

Conclusions: The great majority of myocardial tissues in cyanotic TOF indicate pre-existing hypertrophic, degenerative, and fibrotic changes. Perivascular fibrosis affects the diastolic compliance of the right ventricle and may account for the absence of improvement of late diastolic relaxation $\left(\mathrm{a}^{\prime}\right)$ and greater postoperative Prv/Plv in the absence of a residual surgical lesion. (J Thorac Cardiovasc Surg 2019;158:1173-83)

In the present era, early surgical correction for tetralogy of Fallot (TOF) is achieved with low mortality and excellent

\footnotetext{
From Departments of ${ }^{\mathrm{a}}$ Thoracic and Cardiovascular Surgery, ${ }^{\mathrm{b}}$ Cardiac Pathology, ${ }^{c}$ Biostatistics, and ${ }^{\mathrm{d}}$ Cardiac Anaesthesia, All India Institute of Medical Sciences, New Delhi, India.

Received for publication June 2, 2018; revisions received March 20, 2019; accepted for publication March 30, 2019; available ahead of print May 24, 2019.

Address for reprints: Ujjwal Kumar Chowdhury, MCh, Diplomate NB, Department of Cardiothoracic and Vascular Surgery, All India Institute of Medical Sciences, New Delhi-110029, India (E-mail: ujjwalchow@rediffmail.com or ujjwalchowdhury@ gmail.com).

$0022-5223 / \$ 36.00$

Copyright (C) 2019 by The American Association for Thoracic Surgery

https://doi.org/10.1016/j.jtcvs.2019.03.118
}

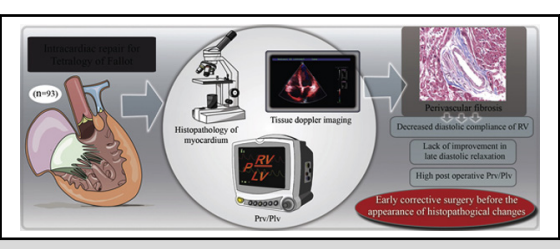

Myocardial biopsy, tissue Doppler, and postoperative Prv/Plv in TOF.

\section{Central Message}

All TDI-derived variables except $\mathrm{a}^{\prime}$ improve over time, along with a significant reduction of right-to-left ventricular peak systolic pressure ratio in repaired TOF without perivascular fibrosis.

\section{Perspective}

All tissue Doppler imaging-derived variables except $\mathrm{a}^{\prime}$ improve after corrective surgery for tetralogy of Fallot without perivascular myocardial fibrosis, along with a significant reduction of peak systolic right-to-left ventricular pressure ratio. Absence of improvement of $a^{\prime}$ may be the causative factor for greater incidence of low cardiac output in these patients.

See Commentary on page 1184 . 


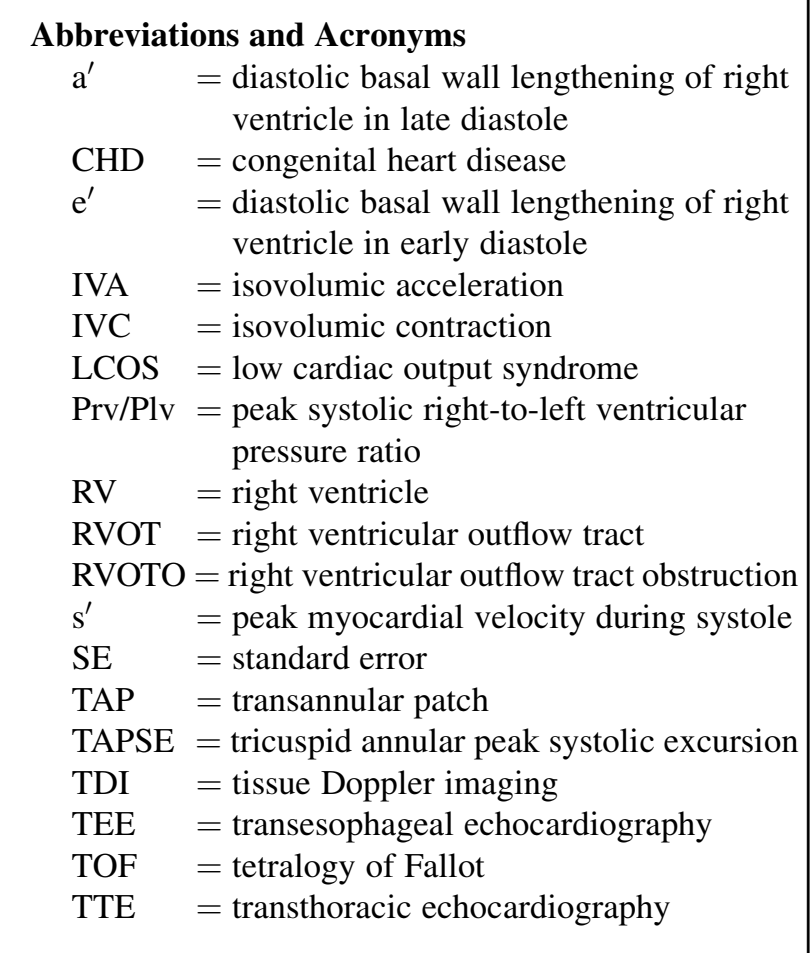

prolonged ventilation, and inotropic support in the absence of any residual (correctable) surgical lesions. ${ }^{1-4}$

Systolic function is usually normal in these patients. Abnormalities in right ventricle (RV) diastolic function in the immediate postoperative period have been incriminated in this clinical behavior. ${ }^{5,6}$ Using tissue Doppler imaging (TDI), investigators have shown pre-existing diastolic dysfunction in some patients that worsened significantly after surgery. ${ }^{5-8}$ In our previous investigation, we demonstrated that the majority of myocardial tissue in cyanotic TOF shows ultrastructural hypertrophic and degenerative changes that are more pronounced in older, severely cyanosed patients. ${ }^{9}$

However, the implication of the pre-existing myocardial histopathologic abnormalities as a causative factor for postoperative myocardial dysfunction has not been hitherto objectively addressed. With this background, we conducted this prospective study to elucidate the histopathologic characteristics of the resected right ventricular outflow tract (RVOT) muscle, postoperative peak right-to-left ventricular systolic pressure ratio (Prv/Plv), and TDI parameters and study the relationship among them (Figure 1).

\section{PATIENTS AND METHODS}

This study conforms to the principles outlined in the declaration of Helsinki and was approved by the Institutional Ethics Committee. Patients were enrolled in the study protocol after we obtained informed written consent from parents/guardians.

\section{Patient Selection Criteria}

This study included survivors of repaired TOF more than 1 year after operation. Patients with TOF with pulmonary atresia, double-outlet RV, complete atrioventricular septal defect, or complete heart block were not included. In addition patients with repaired TOF with (1) residual intracardiac shunting, (2) pulmonary stenosis (Doppler right ventricular outflow tract gradient $\geq 30 \mathrm{~mm} \mathrm{Hg}$ ), and (3) significant ventricular arrhythmias (Lown grade $>2$ ) were also excluded.

Between January 2010 and December 2016, 115 consecutive patients (71 males) undergoing intracardiac repair of TOF at All India Institute of Medical Sciences, New Delhi, operated by a single surgeon (corresponding author) underwent serial TDI and histopathologic analysis. Twenty-two patients were excluded because of in-hospital or late death $(n=6)$, complete heart block $(n=1)$, and morphologic artifacts in histopathology examination resulting from inadequate tissue fixation $(\mathrm{n}=15)$. The examiners were blind to demographic, procedural, and hemodynamic data.

Descriptive characteristics of all patients $(n=93)$ are depicted in Table 1. Standard cardiopulmonary bypass, myocardial preservation techniques, and modified ultrafiltration were used in all patients. Intracardiac repair was performed with a transatrial, transpulmonary approach in $68(73.1 \%)$ patients and a trans-right atrial approach in $25(26.8 \%)$ patients. In $63(67.8 \%)$ patients, a transannular patch was used (Video 1). The RVOT and pulmonary annulus were measured using a Hegar dilator, and a z score was calculated from a nomogram. ${ }^{10}$ Our protocol was to avoid both ventriculotomy and/ or transannular patching in patients with a pulmonary annulus z score greater than -3 , to preserve both RV and pulmonary valve function. Whenever possible, we used the transatrial \pm transpulmonary approach, accepting a postoperative Prv/Plv ratio $\geq 0.7$ when we were quite sure that residual obstruction was due to extreme cephalad deviation of the infundibular septum (and not due to residual infundibular stenosis or residual ventricular septal defect) and always in the presence of stable hemodynamics. Intraoperatively, after pulmonary arteriotomy, pulmonary valvular commissurotomy, and muscle resection of the RVOT, the adequacy of RVOT muscle resection was assessed using a Hegar dilator, matched with nomogram and measuring post-cardiopulmonary bypass RVOT gradient on the operation table, thereby excluding hemodynamically significant right ventricular outflow tract obstruction (RVOTO). ${ }^{3,9,10}$ The major aortopulmonary collateral arteries were managed by coil embolization and did not require unifocalization $(\mathrm{n}=24)$. The tissues studied were operatively resected muscle from parietal band of crista supraventricularis. After surgery, pressures in the right and left ventricles were measured and 2-dimensional transesophageal echocardiography (TEE) was performed. We considered the repair to be satisfactory in the presence of stable hemodynamics and no significant residual defects on TEE.

Transesophageal and transthoracic 2-dimensional (TTE), color flow, Doppler echocardiography, and TDI were performed using a Philips iE33 ultrasound system (Koninklijke Philips N.V., Amsterdam, The Netherlands) with 2.0 to 5.0 MHZ transducer and an HP Sonos 5500 machine (Hewlett Packard, Andover, Mass). ${ }^{11}$ TDI was performed by TEE preoperatively $(\mathrm{t}=0)$, immediately postoperative $(\mathrm{t}=1)$, and by TTE before discharge $(\mathrm{t}=2)$, at 6 -month $(\mathrm{t}=3)$, and at 1 -year $(\mathrm{t}=4)$ intervals. The parameters recorded were isovolumic acceleration (IVA), isovolumic contraction (IVC), peak myocardial velocity during systole $\left(\mathrm{s}^{\prime}\right)$, the diastolic basal wall lengthening of right ventricle in early diastole $\left(\mathrm{e}^{\prime}\right)$, and the diastolic basal wall lengthening of right ventricle in late diastole $\left(a^{\prime}\right)$ (Appendix E1). ${ }^{9-14}$

\section{Collection and Preparation of Tissues}

Resected RVOT muscle measuring about 4 to $5 \mathrm{~mm}$ in thickness including the crista supraventricularis was subjected to histopathologic evaluation by light microscopy (light microscopy evaluation, staining; see Appendix E1). The techniques of tissue fixation, staining, and grading have been addressed in our earlier publication. ${ }^{9}$ 


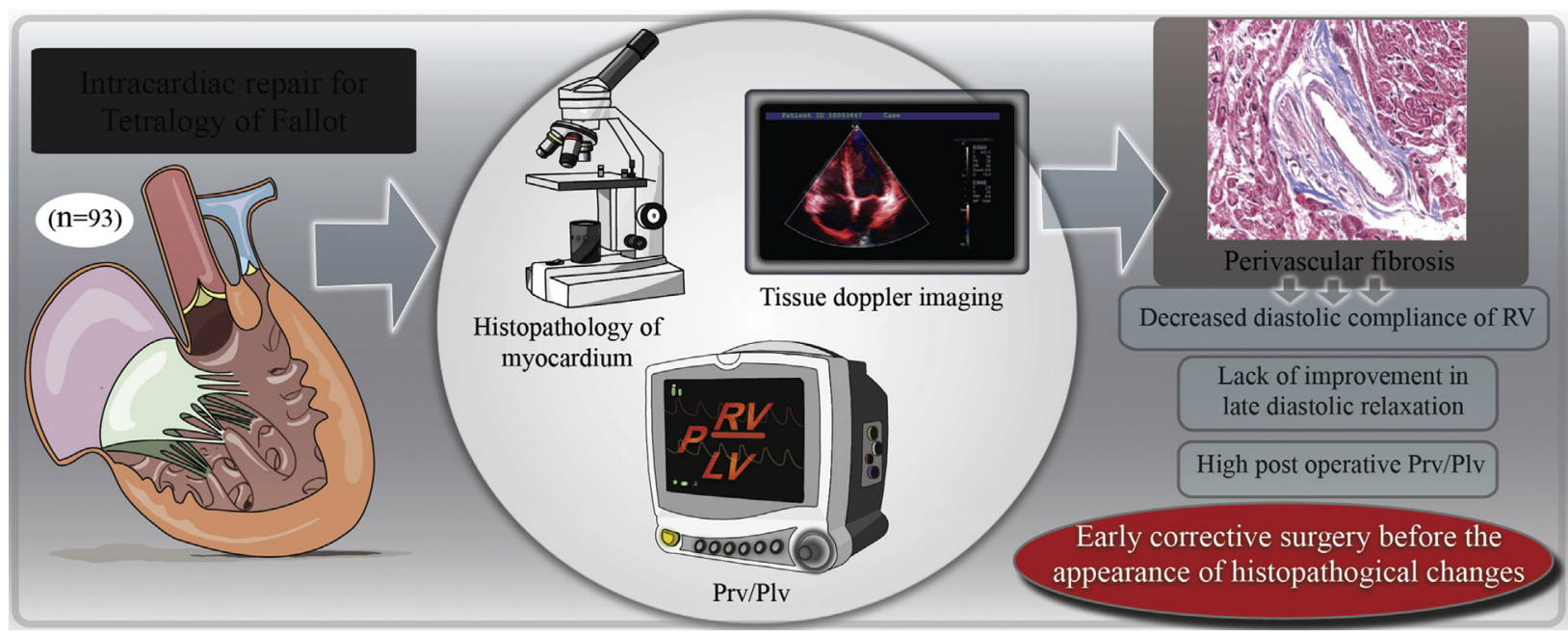

FIGURE 1. Graphic display of the study group $(\mathrm{n}=93)$ showing the inter-relationship among myocardial histopathology, tissue Doppler-derived parameters, and postoperative peak systolic right-to-left ventricular pressure ratio $(\operatorname{Prv} / P l v)$. The absence of improvement of basal wall lengthening of right ventricle $(R V)$ in late diastole in patients with perivascular fibrosis may be responsible for greater postoperative Prv/Plv.

On light microscopy, the sections were evaluated for the following parameters: myocyte hypertrophy, myocyte degeneration, and interstitial fibrosis (perivascular, replacement, or interfiber type). Although each of these parameters were graded as mild, moderate, and severe, for the ease of statistical inference it is denoted as "present" or "absent."

Cellular hypertrophy. Cellular hypertrophy was defined as an alteration of cardiac myocytes with an increase in cell size more than $15 \mu \mathrm{m}$ in diameter with significant nuclear enlargement.

Myocyte degeneration. Myocyte degeneration typically elucidated by myocytolysis without formation of hypercontraction bands. These are considered as mild when there is focal loss of filaments (preferably thick myosin), focal $\mathrm{Z}$ band thickening, fragmentation, and sarcolemmal accumulation of Z-band material. These changes are classified as severe when accompanied with cellular atrophy, cellular and myofibrillar degeneration and lysis, proliferation of sarcoendoplasmic reticulum, and myelin figure formation."

Interstitial/perivascular/intermyocellular fibrosis. Fibrosis is defined as an increase in pericellular matrix with deposition of mature collagen bundles, microfibrils, and other ground substances.

\section{Postoperative Studies}

Between January 2010 and December 2016 (closing interval), patients underwent clinical examination, electrocardiogram, and echocardiography at discharge, 6 months, and at 1 year with minimum of 12 months of follow-up.

\section{Statistical Analysis}

Statistical analysis was carried out using Stata 12.0 (StataCorp LP, College Station, Tex). Continuous data are presented as mean \pm standard deviation, whereas categorical variables are presented as frequency distribution and percentage. Normality assumptions of echocardiographic variables were assessed using the Shapiro-Wilks test. For data analysis, the study population was grouped based on histologic findings, namely, myocyte hypertrophy, myocyte degeneration, and perivascular/interstitial fibrosis. As stated previously, each TDI-derived parameter was measured at 5 points of time: preoperatively $(\mathrm{t}=0)$, immediate postoperatively $(\mathrm{t}=1)$, at discharge $(\mathrm{t}=2)$, at 6 months $(t=3)$, and at 12 months $(t=4)$. Given the difference in time intervals, a random effects model had been used to obtain the results of the longitudinal analysis and the trajectories were considered as repeated measures data (Table 2, Figures E1-E7). Since the relationship between myocardial histopathology, TDI-derived variables, and postoperative Prv/Plv is longitudinal over time among groups, they were compared using longitudinal models with group designation as a variable within the model along with time and TDI-derived parameters as the dependent variable.

TDI-derived parameters over a period of time between the normal and abnormal categories of myocardium were analyzed using a generalized linear random effects model by xtreg command in Stata 12.0. The results were reported as regression coefficient (standard error [SE]). Progression to greater TDI-derived values during follow-up denotes improvement. $P<.05$ was considered statistically significant.

\section{RESULTS}

Age at operation of the study group was 18 months to 26 years (mean $7.02 \pm 5.35$ years) with $35.4 \%(n=33)$ of patients being younger than 3 years of age. There were $4(3.5 \%)$ perioperative deaths due to massive pulmonary hemorrhage $(\mathrm{n}=1)$, intractable ventricular arrhythmias $(n=1)$, and LCOS $(n=2)$. We had to revise the transannular patch $(\mathrm{n}=2)$ and perform more aggressive muscle resection $(\mathrm{n}=1)$ in 3 patients. There were $2(1.8 \%)$ late deaths due to ventricular arrhythmias $(\mathrm{n}=1)$ and late-onset complete heart block $(\mathrm{n}=1)$.

All patients were routinely started on dopamine $\left(4 \mu \mathrm{g} \cdot \mathrm{kg}^{-1} \cdot \mathrm{min}^{-1}\right)$ to increase renal perfusion and sodium nitroprusside $\left(0.5 \mu \mathrm{g} \cdot \mathrm{kg}^{-1} \cdot \mathrm{min}^{-1}\right)$ to reduce afterload. Patients considered to have LCOS $(\mathrm{n}=55)$ required dopamine $\left(4-10 \mu \mathrm{g} \cdot \mathrm{kg}^{-1} \cdot \mathrm{min}^{-1}\right)$, dobutamine $(5-10$ $\left.\mu \mathrm{g} \cdot \mathrm{kg}^{-1} \cdot \mathrm{min}^{-1}\right)$, epinephrine $\left(0.01-0.1 \mu \mathrm{g} \cdot \mathrm{kg}^{-1} \cdot \mathrm{min}^{-1}\right)$, and milrinone $(50 \mu \mathrm{g} / \mathrm{kg}$ intravenous bolus followed by $0.375-0.75 \mu \mathrm{g} \cdot \mathrm{kg}^{-1} \cdot \mathrm{min}^{-1}$ ), alone or in combination. Mean duration of inotropic requirement was $48.14( \pm 20.8)$ hours (range, 36-104 hours). Forty-nine $(71.0 \%)$ patients 
TABLE 1. Demographic, operative, and perioperative details of the survivors of repaired tetralogy of Fallot of the study group $(n=93)$

\begin{tabular}{lc}
\hline \multicolumn{1}{c}{ Variables } & Number $(\%)$ \\
\hline $\begin{array}{l}\text { Age at operation, y } \\
<3\end{array}$ & $33(35.4)$ \\
$\geq 3$ & $60(64.6)$ \\
Age at operation, y, mean \pm SD (range) & $7.02 \pm 5.35$ \\
& $(18$ mo-26 ys) \\
Sex & \\
$\quad$ Male & $71(76.3)$ \\
Female & $22(23.7)$ \\
Preoperative oxygen saturation & \\
$\quad<80 \%$ & $62(66.6)$ \\
$\geq 80$ & $31(33.4)$ \\
Hematocrit, \% & \\
$\quad \geq 45 \%$ & $61(66.6)$ \\
$<45 \%$ & $32(33.4)$ \\
Aortic override & \\
$\geq 50 \%$ & $60(64.5)$ \\
$<50 \%$ & $33(35.5)$ \\
Previous Blalock-Taussig shunt & $6(6.5)$ \\
Yes & $87(93.5)$ \\
No & \\
Major aortopulmonary collateral arteries & $24(25.8)$ \\
Present & $69(74.2)$ \\
Absent &
\end{tabular}

Perioperative supraventricular and ventricular arrhythmias

$\begin{array}{ll}\text { Yes } & 28(30) \\ \text { No } & 65(69.9) \\ \text { Transannular patch } & \\ \text { Yes } & 63(67.7) \\ \text { No } & 30(32.3)\end{array}$

Pulmonary regurgitation

$\begin{array}{ll}\text { Present } & 63(67.7)\end{array}$

Absent 30 (32.3)

Congestive heart failure

$\begin{array}{ll}\text { Present } & 55(59.1)\end{array}$

Absent 38 (40.9)

Low cardiac output

$\begin{array}{ll}\text { Present } & 55(59.1) \\ & 38(40.9)\end{array}$

$\begin{array}{lc}\text { Reoperations } & \\ \text { Yes } & 3(3.2) \\ \text { No } & 90(96.8) \\ \text { Inotropic requirement, h, mean } \pm \mathrm{SD} & 48.14 \pm 20.8 \\ & (36-104) \\ \text { Duration of hospitalization, d, mean } \pm \mathrm{SD} & 8 \pm 5\end{array}$

Peak systolic postrepair right-to-left ventricular pressure ratio
$\geq 0.7$
$45(48.4)$
$<0.7$
$48(51.6)$

(Continued)
TABLE 1. Continued

\begin{tabular}{lc}
\hline \multicolumn{1}{c}{ Variables } & Number $(\%)$ \\
\hline Histology of the myocardium & \\
Normal & $10(10.8)$ \\
Myocardial hypertrophy & $83(89.2)$ \\
Myocytolysis & $78(83.8)$ \\
Perivascular fibrosis & $72(77.4)$ \\
\hline$S D$, Standard deviation.
\end{tabular}

older than 15 years of age had predominant RV dysfunction and $\operatorname{LCOS}(P=.04$; odds ratio, $2.7 ; 95 \%$ confidence interval, 0.9-7.9). These patients had restrictive RV physiology and varying degrees of abnormal myocardial histopathology.

Follow-up was $100 \%$ complete and yielded 459.42 patient-years of data with a mean follow-up time of 59.28 months ( $\mathrm{SD} \pm 19.65$; range 12-84 months). Left ventricular systolic function was normal (ejection fraction $>0.5)$ in $74(79.6 \%)$ and depressed in $19(20.4 \%)$ patients. Fifty-two $(55.9 \%)$ patients had mild and $11(11.8 \%)$ patients had moderate pulmonary regurgitation. Four (4.3\%) patients had mild tricuspid regurgitation. During late follow-up, there were no reoperations for any RVOTO, residual ventricular septal defect, or residual surgical problems. Preoperative electrocardiographic studies demonstrated normal sinus rhythm $(\mathrm{n}=93)$, right ventricular hypertrophy $(\mathrm{n}=93)$, and single uniform ventricular extrasystoles (Lown grade 2, $\mathrm{n}=9$ ). Postoperative studies at a mean follow-up time of $59.28 \pm 19.65$ months demonstrated sinus rhythm $(\mathrm{n}=80)$, incomplete right bundle branch block $(\mathrm{n}=90)$, left bundle branch block $(\mathrm{n}=11)$, junctional ectopic tachycardia $(\mathrm{n}=13)$, and ventricular extrasystoles (Lown grade $2, \mathrm{n}=9$ ).

The functional class at follow-up, need for cardiac medications, development of arrhythmias, ventricular dysfunction, congestive heart failure, and late complications were noted. Eighty-seven $(93.5 \%)$ patients were in New York Heart Association class I/II, and the remaining $(n=6)$ were in New York Heart Association class III. In our previous publication, we investigated the potential risk factors for cellular hypertrophy, myocytolysis, and perivascular fibrosis by forward stepwise logistics regression analysis, and they are not repeated here.

\section{Evolution of Prv/Plv}

The Prv/Plv was assessed on operation table after stabilization of hemodynamics and administration of protamine by direct needle puncture. Intraoperatively, this directly measured pressure was inter-related with TEE $(t=1)$ and using transthoracic echocardiography at $\mathrm{t}=2$ (discharge), $\mathrm{t}=3$ (6 months) and $\mathrm{t}=4$ (12 months).

In all patients, the median Prv/Plv ratio as measured in the operating room was 0.64 (range, $0.3-1.3$ ) with a median 


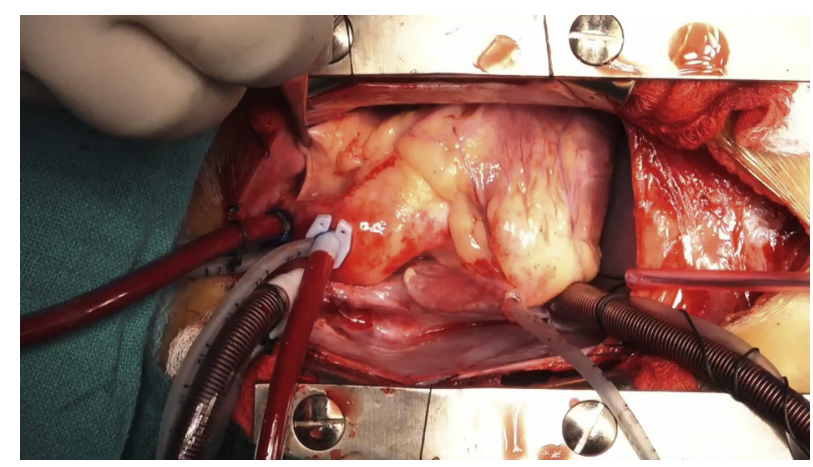

VIDEO 1. A presentation of intracardiac repair of the tetralogy of Fallot using a trans-right atrial and transpulmonary approach. Through median sternotomy, the pericardium is incised to the right of midline and left in situ in between 4-0 silk stay sutures. After aortobicaval cannulation, the fat pad between the aorta and pulmonary artery is incised for individual aortic crossclamping, thus avoiding distortion of the pulmonary artery. Patent ductus arteriosus, if present, is ligated at this stage by McGoon's technique under controlled hypotension. Four stay sutures are placed proximal and distal to the pulmonary valve ring. The mid-portion of the pulmonary artery is incised in between stay sutures. The aorta is crossclamped. Myocardial protection is achieved by administering injection adenosine, cold blood cardioplegia ( $\mathrm{St}$ Thomas II; 4:1) and concomitant topical cardiac cooling using cold saline. Right atriotomy is being performed $1 \mathrm{~cm}$ parallel to the atrioventricular groove for proper visualization of the tricuspid valve, ventricular septal defect and infundibular os. The left ventricle is being vented through the inter-atrial septum using a Medtronic DLP (Medtronic, Minneapolis, Minn) vent. The parietal insertion of the infundibular septum is being excised to relieve right ventricular outflow tract obstruction. Care being taken to avoid excision of the septal insertion of the infundibular septum to avoid injury to the first septal perforator artery. A DLP vent is being placed in the pulmonary artery to obtain a bloodless operative field. Two stay sutures are being placed on the 2 extremes of the anterosuperior portion of the tricuspid valve annulus for proper visualization. The final relief of the right ventricular outflow tract obstruction is being achieved by a combined transpulmonary and trans right atrial approach avoiding injury to the trabeculo septomarginalis and aortic valve. A circumferential muscular resection is being performed around the infundibular os. An appropriately sized Hegar dilator is being inserted through the newly created infundibular os to ensure the adequacy of muscle resection and matched with nomogram, thereby excluding hemodynamically significant right ventricular outflow tract obstruction. The ventricular septal defect is being closed using a Dacron patch and interrupted 5-0 pledgeted Prolene sutures taking care not to injure the atrioventricular bundle, tricuspid valve and the aortic valve. The patent foramen ovale is being closed directly. The septal leaflet of the tricuspid valve is being mobilized releasing tethering if any to avoid iatrogenic tricuspid regurgitation. The tricuspid valve is being checked for competence. A 2- to 3-mm patent foramen ovale is being created for right ventricular decompression in the event of postoperative right ventricular dysfunction. The right atrium is being closed in 2 layers using 5-O polypropylene suture. The aortic crossclamp has been removed. An appropriatesized untreated pericardial patch is being sutured over the pulmonary artery on a beating perfused heart. Card being taken not to oversize or undersize the pulmonary valve ring and pulmonary artery. The cusps of the pulmonary artery are being retained to obtain a bicuspid configuration, thus minimizing postoperative pulmonary regurgitation. The second layer of the right atriotomy is closed to achieve perfect hemostasis. Video available at: https:// www.jtcvs.org/article/S0022-5223(19)30899-2/fulltext. pressure gradient in RVOT of $19.6 \mathrm{~mm} \mathrm{Hg}$ (range 15-26). Forty-five $(48.4 \%)$ patients had a Prv/Plv ratio $\geq 0.7$, ranging from 0.7 to 1.3 .

After a mean follow-up of $59.28(\mathrm{SD} \pm 19.65)$ months, the mean Prv/Plv decreased from $0.9 \pm 0.34$, range 0.3 1.3 , to $0.5 \pm 0.15$, range $0.2-0.9$ (t1-t $4, P<.001$ ) among patients of the entire study group; in patients with repaired TOF with greater Prv/Plv $\geq 0.7$, the reduction was from $0.80 \pm 0.42$ to $0.6 \pm 0.12(P=.001)$ and in patients with Prv/Plv <0.7, it was from $0.5 \pm 0.16$ to $0.41 \pm 0.24$ $(P=.12)$. In patients with repaired TOF with greater Prv/ Plv $\geq 0.7$, there was statistically significant decrease in Prv/Plv at all points of time with overall significant decrease over 1 year in the postoperative period $(P<.001)$ (Figure 2 ). The RVOT gradient was not taken into consideration for data analysis.

\section{Data Analyses and Study Interpretation of the Pre- and Postoperative TDI-Derived Variables, Postoperative Peak Systolic Prv/Plv, and Myocardial Histopathology}

Of 115 specimens, 15 were rejected for histopathologic analysis due to inadequate fixation. Ten $(10.8 \%)$ myocardial specimens were found to be histologically normal. A total of $83(89.2 \%)$ specimens had myocyte hypertrophy, which was moderate in $29(34.9 \%)$ and severe in 19 $(22.9 \%)$ specimens. These specimens exhibited significant cellular enlargement (diameter over $20 \mu \mathrm{m}$ with nucleomegaly, irregular cell shapes, multiple intercalated discs, and bizarre accumulation of Z-band material (Figure 3, $A$ and $B$ ). Myocytolysis was exhibited by $83.8 \%(\mathrm{n}=78)$, of which $20(25.6 \%)$ were moderate and $17(21.8 \%)$ were severe (Figure 3, $A$ and $B)$. Perivascular/interstitial fibrosis was exhibited by $77.4 \%$ $(\mathrm{n}=72)$ myocardial specimens, which was moderate in $19(26.3 \%)$ and severe in $11(15.3 \%)$ (Figure $4, A$ and $B$ and Figure 5, $A-F)$. The grades of cardiomyocyte hypertrophy, myocyte degeneration, and myocardial fibrosis were grouped as normal and abnormal as the sample size in different grades of severity were insufficient for individual data analysis.

All parameters of the baseline characteristics, namely age at operation, sex, preoperative systemic arterial oxygen saturation, hematocrit, degree of aortic override, previous palliation, presence of major aortopulmonary collateral arteries, perioperative supraventricular and ventricular arrhythmias, requirement of transannular patch (TAP), degree of pulmonary regurgitation, tricuspid regurgitation, LCOS, left ventricular ejection fraction, reoperations, TDI-derived parameters, and peak systolic postoperative Prv/Plv were taken into consideration for data analysis. Generalized linear random effects model using xtreg command revealed the following: 
TABLE 2. Assessment of TDI-derived parameters over a period of time between the normal and abnormal categories of myocardium (cardiomyocyte hypertrophy, myocyte degeneration, and interstitial fibrosis) of the study group $(\mathbf{n}=\mathbf{9 3})$

\begin{tabular}{|c|c|c|c|c|c|c|}
\hline \multirow[b]{2}{*}{ TDI variables } & \multicolumn{2}{|c|}{$\begin{array}{l}\text { Myocyte hypertrophy } \\
\text { (column 1) }\end{array}$} & \multicolumn{2}{|c|}{$\begin{array}{l}\text { Myocyte degeneration } \\
\text { (column 2) }\end{array}$} & \multicolumn{2}{|c|}{$\begin{array}{l}\text { Perivascular/interstitial fibrosis } \\
\text { (column 3) }\end{array}$} \\
\hline & $\beta$ (SE) & $P$ value & $\beta$ (SE) & $P$ value & $\beta$ (SE) & $P$ value \\
\hline \multicolumn{7}{|l|}{ TAPSE, $\mathrm{cm}$} \\
\hline Time & $0.48(0.05)$ & $<.001$ & $0.48(0.05)$ & $<.001$ & $0.48(0.05)$ & $<.001$ \\
\hline Group & $-1.55(0.97)$ & .11 & $-0.03(0.84)$ & .9 & $-1.12(1.23)$ & .3 \\
\hline \multicolumn{7}{|l|}{ IVA, $\mathrm{cm} / \mathrm{s}^{2}$} \\
\hline Time & $0.29(0.05)$ & $<.001$ & $0.29(0.05)$ & $<.001$ & $0.29(0.05)$ & $<.001$ \\
\hline Group & $-0.69(1.87)$ & .7 & $-1.68(1.57)$ & .28 & $-0.49(1.03)$ & .63 \\
\hline \multicolumn{7}{|l|}{$\mathrm{IVC}, \mathrm{cm} / \mathrm{s}$} \\
\hline Time & $0.31(0.04)$ & $<.001$ & $0.31(0.04)$ & $<.001$ & $0.31(0.04)$ & $<.001$ \\
\hline Group & $-1.36(0.91)$ & .13 & $0.06(0.79)$ & .9 & $-0.82(1.15)$ & .4 \\
\hline \multicolumn{7}{|l|}{$\mathrm{s}^{\prime}, \mathrm{cm} / \mathrm{s}$} \\
\hline Time & $0.41(0.04)$ & $<.001$ & $0.41(0.04)$ & $<.001$ & $0.41(0.04)$ & $<.001$ \\
\hline Group & $-1.31(0.85)$ & .12 & $0.46(0.73)$ & .5 & $-1.24(1.06)$ & .24 \\
\hline \multicolumn{7}{|l|}{$\mathrm{e}^{\prime}, \mathrm{cm} / \mathrm{s}$} \\
\hline Time & $0.36(0.03)$ & $<.001$ & $0.36(0.03)$ & $<.001$ & $0.36(0.04)$ & $<.001$ \\
\hline Group & $-0.56(0.68)$ & .4 & $0.42(0.58)$ & .4 & $-1.52(0.83)$ & .06 \\
\hline \multicolumn{7}{|l|}{$\mathrm{a}^{\prime}, \mathrm{cm} / \mathrm{s}$} \\
\hline Time & $0.09(0.04)$ & .01 & $0.09(0.04)$ & .01 & $0.17(0.15)$ & .2 \\
\hline Group & $-1.45(0.81)$ & .07 & $0.75(0.70)$ & .2 & $1.99(2.31)$ & .38 \\
\hline \multicolumn{7}{|l|}{ Postoperative Prv/Plv } \\
\hline Time & $-0.47(0.004)$ & $<.001$ & $-0.04(0.004)$ & $<.001$ & $-0.47(0.004)$ & $<.001$ \\
\hline Group & $0.66(0.06)$ & .3 & $0.08(0.05)$ & .1 & $-0.07(0.08)$ & .3 \\
\hline
\end{tabular}

Columns 1, 2, and 3 are groups according to histologic abnormality namely, myocyte hypertrophy, degeneration, and fibrosis. Time: Each TDI variables and postoperative Prv/Plv were measured at 5 points of time: preoperatively $(\mathrm{t}=0)$, immediate postoperatively $(\mathrm{t}=1)$, before discharge $(\mathrm{t}=2)$, at 6 months $(\mathrm{t}=3)$, and at 12 months $(\mathrm{t}=4)$. Group: Group refers to normal and abnormal categories of myocardium. TDI, Tissue Doppler imaging; $\beta$, regression coefficient; $S E$, standard error; TAPSE, tricuspid annular peak systolic excursion; IVA, isovolumic acceleration; $I V C$, isovolumic contraction; $s^{\prime}$, peak myocardial velocity during systole; $e^{\prime}$, diastolic basal wall lengthening of right ventricle in early diastole; $a^{\prime}$, diastolic basal wall lengthening of right ventricle in late diastole; $\operatorname{Prv} / P l v$, peak systolic right-to-left ventricular pressure ratio.

1. Compared with normal histology, patients with cardiomyocyte hypertrophy had a lower initial tricuspid annular peak systolic excursion (TAPSE), IVA, IVC, $\mathrm{s}^{\prime}, \mathrm{e}^{\prime}$, and $\mathrm{a}^{\prime}$ values. However, there was significant improvement in TAPSE, IVA, IVC, $\mathrm{s}^{\prime}, \mathrm{e}^{\prime}$, and $\mathrm{a}^{\prime}$ values and significant reduction of postoperative Prv/Plv during follow-up $(\beta=-0.47, \mathrm{SE}=0.004, P<.001)$. At the same time, patients with normal histology had greater

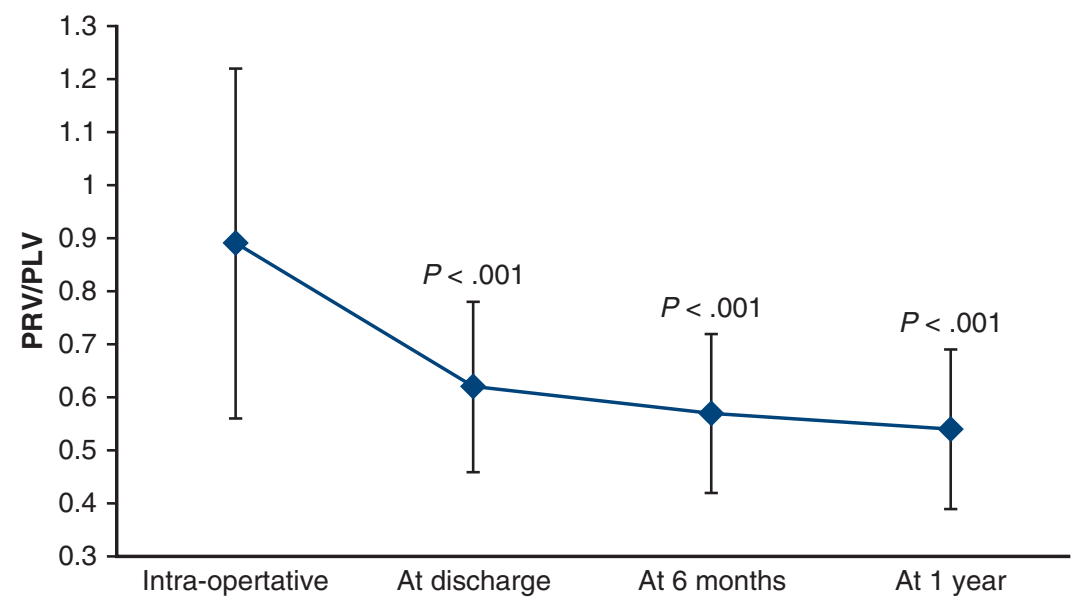

FIGURE 2. Line graph showing evolution of postoperative peak systolic right-to-left ventricular pressure ratio (Prv/Plv) during the designated follow-up period of survivors of repaired tetralogy of Fallot undergoing data analysis $(\mathrm{n}=93)$. There was a statistically significant reduction of postoperative Prv/Plv in all patients at all times during follow-up $(P<.001)$. 

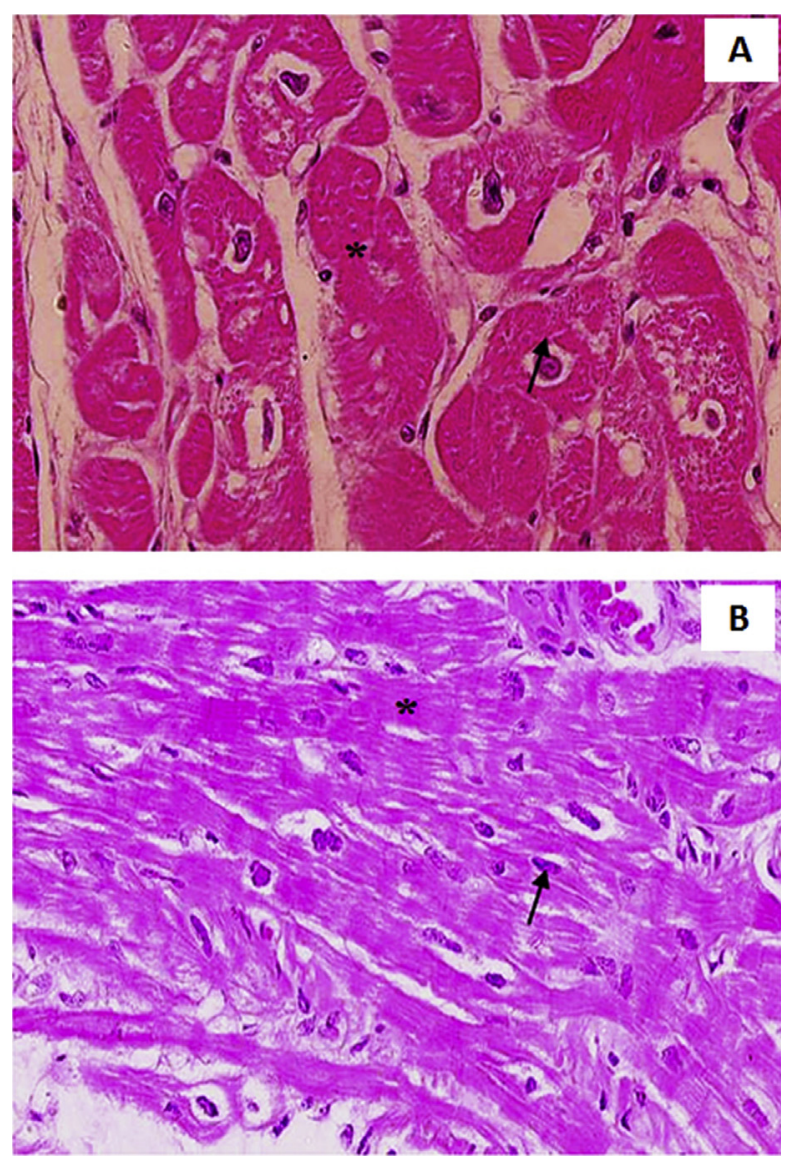

FIGURE 3. $A$ and $B$, Photomicrographs of the right ventricular outflow tract biopsy specimen of patients with tetralogy of Fallot (light microscopy, hematoxylin and eosin stain $\times 20$ ) showing myocyte hypertrophy (asterisk) with large hyperchromatic nuclei (black arrow).

reduction of postoperative Prv/Plv as compared with patients with myocyte hypertrophy. However, none of the changes in TDI-derived parameters and postoperative Prv/Plv between patients with and without myocyte hypertrophy reached statistical significance (Table 2; Figures E1-E7).

2. In patients with myocytolysis, there was a significant improvement of TAPSE, IVA, IVC, $\mathrm{s}^{\prime} \mathrm{e}^{\prime}$, and $\mathrm{a}^{\prime}$ during the follow-up period. There was significant reduction of postoperative Prv/Plv of all patients during followup $(\beta=-0.04, \mathrm{SE}=0.004, P<.001)$ (Table 2; Figures E1-E7). Patients with normal histology had greater reduction of postoperative Prv/Plv as compared with patients with myocyte degeneration. However, it did not reach statistical significance $(\beta=0.08$, $\mathrm{SE}=0.05, P=.1)$ (Table 2; Figures E1-E7).

3. In patients with myocardial fibrosis, there was significant improvement in TAPSE, IVA, IVC, $\mathrm{s}^{\prime}, \mathrm{e}^{\prime}$, and postoperative Prv/Plv values during the follow-up period. There was no improvement in the diastolic basal wall lengthening of $\mathrm{RV}$ in late diastole $\left(\mathrm{a}^{\prime}\right)$. Compared with
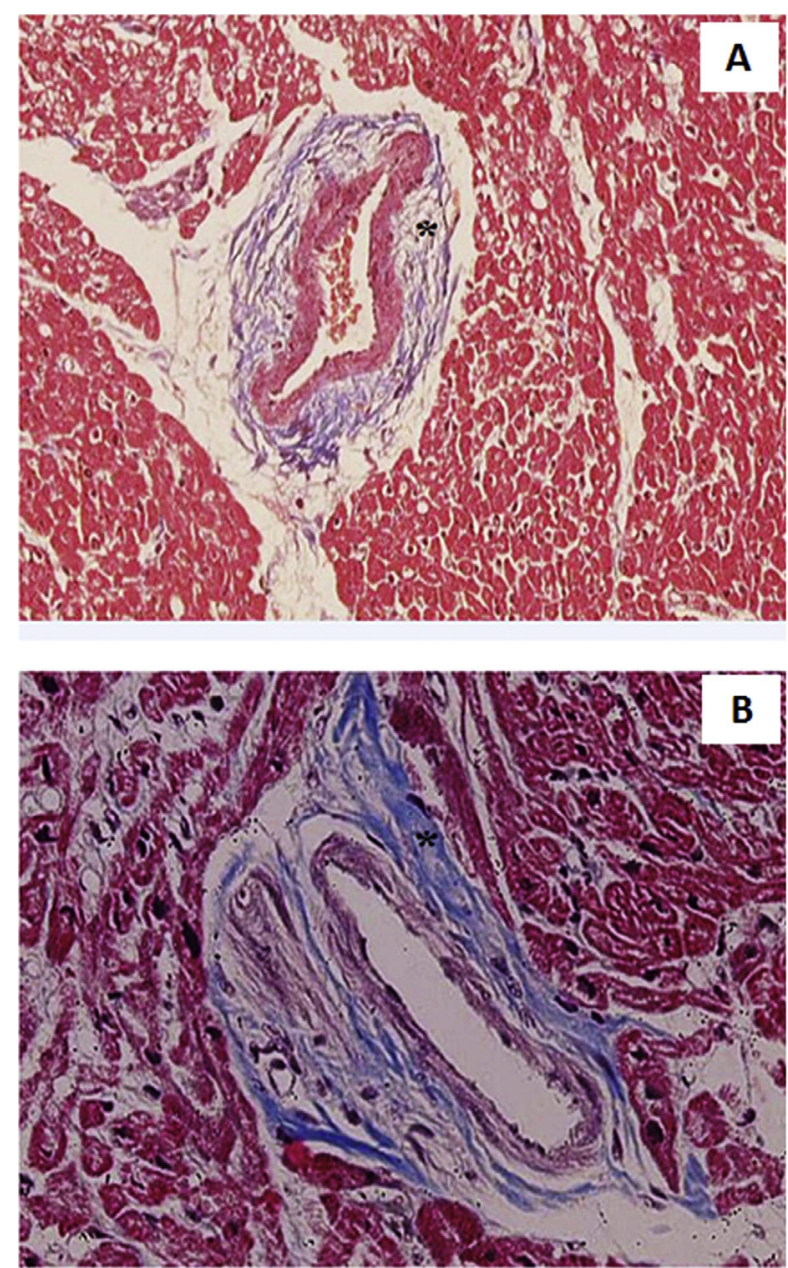

FIGURE 4. A and B, Photomicrographs of the right ventricular outflow tract biopsy specimen of patients with tetralogy of Fallot (light microscopy, Masson trichrome stain $\times 20$ ) showing perivascular fibrosis (asterisk) typical of tetralogy of Fallot.

patients with normal histology, patients with myocardial fibrosis had lower values of TAPSE, IVA, IVC, $\mathrm{s}^{\prime}$, and $\mathrm{e}^{\prime}$. Although there was improvement of postoperative Prv/ Plv in patients with myocardial fibrosis as compared with normal histology, the values were not statistically significant $(\beta=-0.07, \mathrm{SE}=0.08, P=.3$ ), (Table 2; Figures E1-E7).

\section{DISCUSSION}

As far as we could establish, there have been no studies addressing the inter-relationship among histopathology of the RV myocardium, postrepair Prv/Plv, and TDI-derived myocardial velocities in repaired TOF.

The functional status of the myocardium determines the long-term prognosis of patients with cyanotic congenital heart diseases (CHD). Degenerated myocytes do not contribute to the contractile function of the heart. ${ }^{1,3-10,15-18}$ Several investigators have highlighted the role of the 

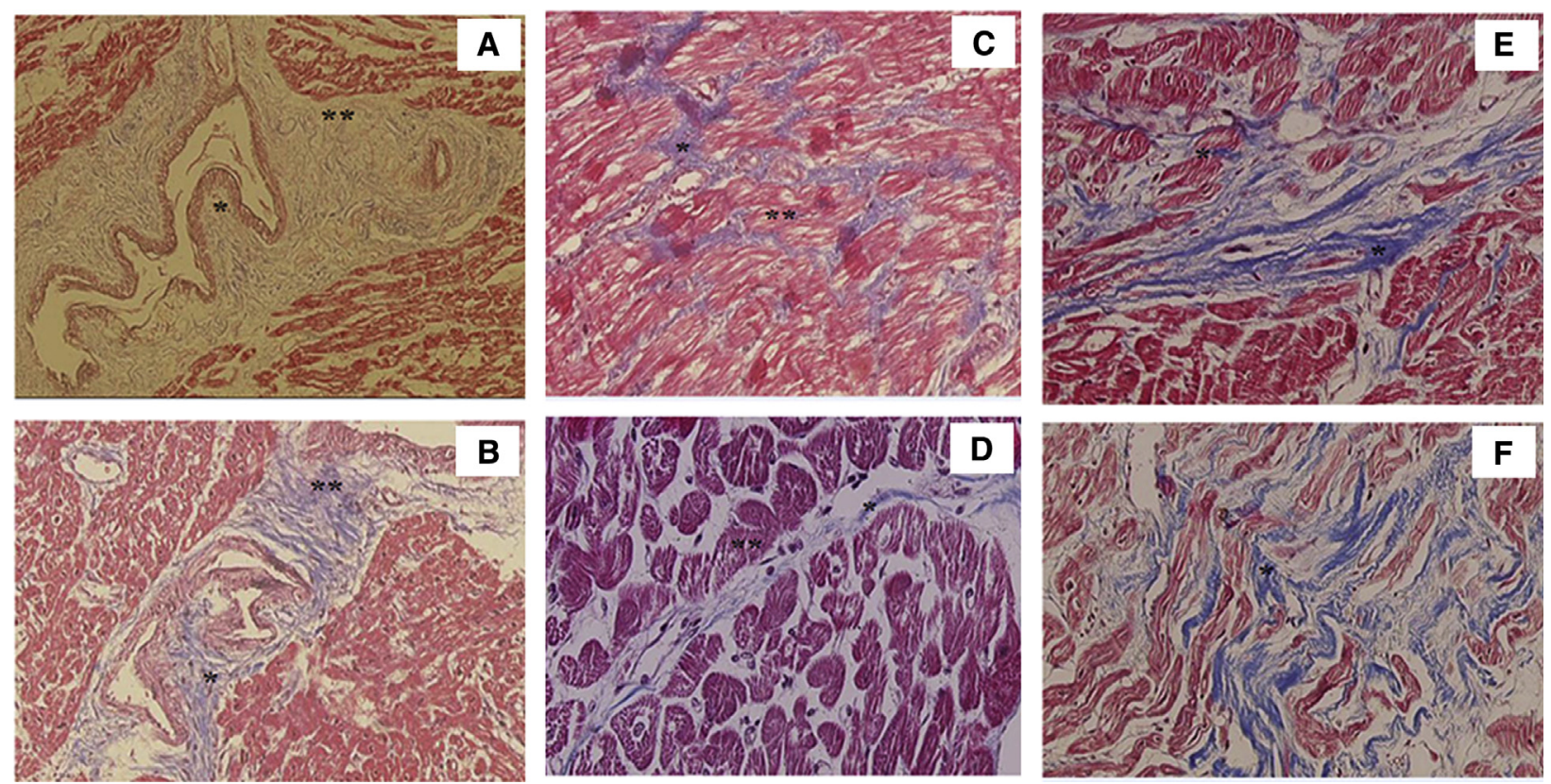

FIGURE 5. A-F, Photomicrographs of the right ventricular outflow tract biopsy specimen of patients with tetralogy of Fallot (light microscopy, Masson trichrome stain $\times 20$ ) showing varying degrees of perivascular (asterisk) and interstitial (double asterisk) fibrosis. C and D show varying degrees of muscle hypertrophy and myocardial disarray; E and F show extensive interstitial fibrosis (double asterisk).

"myocardial factor" in patients with cyanotic CHD including TOF. $^{3-5,17,18}$ Whether this is related to downregulation of receptors on the myocardial cells or to progressive alteration in myocyte architecture remains to be elucidated. $^{15-17}$

\section{Myocardial Histopathology in TOF}

Latent biventricular dysfunction and decreased left ventricular contractile reserve have been described in repaired TOF. ${ }^{6,15,17}$ Krymsky $^{19}$ in a histologic study demonstrated moderate-to-severe degrees of myocyte degeneration, endocardial thickening, and fibrosis in patients with unrepaired TOF with biventricular dysfunction. Myocardial hypertrophy leads to myocardial ischemia, degeneration, and ultimately fibrosis., $3,20-22$ During surgery, these hearts are subjected to intentional ischemia during aortic crossclamping. Adequate myocardial protection still remains a challenge in cyanotic hearts. Fibrosis, an irreversible change at tissue level compounded with RV muscular hypertrophy, further aggravates the already-stressed myocardial oxygen delivery and function..$^{21,22}$

Although it is impossible to relate an LCOS state directly to a specific myocardial morphologic alteration, such a relation is suggested by the presence of disorganization and degeneration in the heart muscle of adult TOF. ${ }^{10,19-23} \mathrm{We}$ concur with other investigators in that the frequency of ventricular arrhythmia increases in older patients with TOF. ${ }^{10,15-17}$ Necropsy studies have shown extensive endocardial thickening and perivascular fibrosis in adults with uncorrected TOF, unlike younger patients. ${ }^{22}$

In our previous investigation on 183 patients undergoing intracardiac repair of TOF aged 12 months to 42 years, we demonstrated that the degree of preoperative hypoxemia (systemic arterial oxygen saturation $<80 \%$ ), increased preoperative hematocrit ( $\geq 45 \%$ ), age $\geq 4$ years, and right ventricular end-diastolic pressure ratio $\geq 12 \mathrm{~mm} \mathrm{Hg}$ as the "potential" risk factors for cardiomyocyte degeneration and interstitial fibrosis. These changes could be the anatomic substrate for compliance or contractile abnormalities of the ventricle in patients with TOF. ${ }^{\text {? }}$

\section{TDI-Derived Variables and Myocardial Histopathology}

TDI has high temporal and spatial resolution and is thus suited for accurately measuring velocities of myocardium at specific locations. The literature is rife with investigators comparing TDI with radionuclide studies and magnetic resonance imaging in patients with TOF. ${ }^{13,14}$ Unlike a conventional TTE, most TDI-derived variables are preload independent. Among the TDI-derived variables, TAPSE and $\mathrm{s}^{\prime}$ have been shown to correlate well with global systolic RV function. The $\mathrm{s}^{\prime}(<10 \mathrm{~cm} / \mathrm{s})$ is an independent predictor of RV dysfunction and reduced exercise capacity in repaired TOF. ${ }^{14}$ It has been shown by Shan and colleagues ${ }^{24}$ that systolic $\left(\mathrm{s}^{\prime}\right)$ and early diastolic velocities $\left(\mathrm{a}^{\prime}\right)$ of left heart measured by TDI are dependent on myocardial fibrosis and beta adrenoreceptor density. 
In this study, TAPSE and $s^{\prime}$ values were consistently lower in patients with myocardial hypertrophy, myocardial degeneration, and perivascular/interstitial fibrosis (Table 2). Postoperatively, there was a significant improvement in TAPSE, IVA, IVC, $\mathrm{s}^{\prime}, \mathrm{e}^{\prime}$, and $\mathrm{a}^{\prime}$ values in all patients with myocardial hypertrophy and myocytolysis as compared with normal histology during follow-up. Although there was significant improvement in TAPSE, IVA, IVC, $\mathrm{s}^{\prime}$, and $\mathrm{e}^{\prime}$ values, there was no improvement in diastolic basal wall lengthening of RV in late diastole $\left(a^{\prime}\right)$ during the follow-up period in patients with myocardial fibrosis. (Table 2; Figures E1-E7).

Significant diastolic dysfunction of the RV in repaired TOF may produce a "restrictive physiology" in which the stiff RV demonstrates little true filling and behaves as an almost passive conduit for pulmonary blood flow. Its prevalence in the literature ranges from $28 \%$ to $52 \%{ }^{5,25}$ The restrictive RV physiology may relate to a process of endomyocardial fibrosis intrinsic to the disease, ventriculotomy, pulmonary regurgitation, and interposition of patches in the interventricular septum and the infundibulum. ${ }^{5,24,25}$ It also seems to be influenced by the immaturity of the RV, which adapts to the aggressions of extracorporeal circulation, cardioplegia, and hypothermia. ${ }^{5,24,25}$ Whether the diastolic dysfunction seen in operated patients of TOF is detrimental or advantageous in the long run is not settled. Reduced early and late trans tricuspid diastolic velocities $\left(\mathrm{a}^{\prime}\right.$ and $\left.\mathrm{e}^{\prime}\right)$ have been associated with poorer outcomes after intracardiac repair for $\mathrm{TOF}^{25-27}$ Other investigators have concluded that postoperative restrictive RV physiology may be protective with fewer long-term complications (eg, less QRS widening and chronic pulmonary regurgitation). ${ }^{25-27}$ Our study has demonstrated the presence of moderate-tosevere degrees of perivascular and interstitial fibrosis in majority of these patients (Figure 5, $A-F$ ).

\section{Postoperative Peak Systolic Right-to-Left Ventricular Pressure Ratio and Myocardial Histopathology}

Decisions made at the time of intracardiac repair of TOF have a definite impact on the performance of repair over the subsequent 20 to 30 years and beyond. ${ }^{1-4,15-17}$ Although the primary decision-making on the requirement of TAP is indeed the size of the pulmonary valve ring, postoperative Prv/Plv can guide the surgeons in borderline cases. Many surgical centers will consider using a TAP if immediate postrepair Prv/Plv is $\geq 0.7$. A postoperative Prv/Plv in between 0.8 and 1.0 without TAP and $>0.85$ with TAP adversely affects survival. ${ }^{1-4,15-17}$

Although $67.8 \%(n=63)$ of patients required a limited TAP, $45(48.4 \%)$ patients with repaired TOF continued to exhibit Prv/Plv $\geq 0.7$. We have accepted greater postoperative Prv/Plv because we believed that the annulus was the recommended limit, the muscular resection was deep enough, and the great majority were late presenters with hypertrophied myocardium. We expected a greater Prv/Plv due to the hypercontractile state of the hypertrophied myocardium in the immediate postoperative period and extreme cephalad deviation of the infundibular septum causing dynamic RVOTO.,

The patients with advanced abnormal myocardial histopathology had greater peak systolic Prv/Plv. Among all the abnormal histopathologic findings, perivascular fibrosis was more prevalent among patients with high Prv/Plv. Although there was an improvement of postoperative Prv/ $\mathrm{Plv}$ in patients with myocardial fibrosis as compared with normal histology, the values were not statistically significant $(\beta-0.07$; SE, 0.08, $P=.3$; Table 2$)$.

Careful analysis of the published literature substantiates a significant incidence of LCOS following intracardiac repair of TOF. ${ }^{1-4,8-10}$ The culprit pathophysiologic mechanisms responsible for LCOS in repaired TOF although not specifically addressed or analyzed are multifactorial in nature..$^{1-4,8-10}$ In this study, although it is impossible to relate directly a LCOS state to a specific tissue Doppler-derived variable, such a relation is suggested in patients with greater postoperative Prv/Plv exhibiting absence of improvement of late diastolic relaxation of RV free wall $\left(\mathrm{a}^{\prime}\right)$.

Optimal timing of pulmonary valve replacement in adults with hemodynamically significant pulmonary regurgitation after repaired TOF in childhood is a matter of continuing debate because adverse right ventricular modulation can be irreversible when pulmonary valve replacement is performed too late. Timing solely based on right ventricular volumes may be an oversimplification of a complex issue, particularly in asymptomatic patients. TDI has high temporal and spatial resolution and is thus suited for accurately measuring myocardial velocities at specific locations. Unlike a conventional transthoracic echocardiography, most TDI-derived variables are preload independent and may compliment magnetic resonance imaging by providing a noninvasive estimate of pulmonary regurgitant fraction and ventricular function. ${ }^{1-4,8-10,28-33}$

\section{TDI-Derived Parameters and Prv/PIv}

The strongest predictor of restrictive physiology was the requirement of TAP, which was significantly greater in patients with Prv/Plv $\geq 0.7$ ( $P=.004$; odds ratio, $2.03 ; 95 \%$ confidence interval, 2.09-8.48). During the study period, although all patients exhibited a significant reduction of Prv/Plv late postoperatively, the restrictive physiology (diastolic basal wall lengthening in late diastole $\mathrm{a}^{\prime}$ ) resolved only in patients with postoperative Prv/Plv $<0.7$. Among all TDI-derived variables, TAPSE, IVA, IVC, $\mathrm{s}^{\prime}$, and $\mathrm{e}^{\prime}$ continued to improve to a greater degree in patients with 
myocardial hypertrophy and myocytolysis and in patients with lower Prv/Plv.

\section{Age at Operation, Palliation, and Ventricular Function}

The mean age of the patients in this series was $7.02 \pm 5.35$ years with $64.6 \%(n=60)$ patients being older than 3 years of age. Only $6.5 \%(n=6)$ patients received shunts because the late presentation of CHD is not unusual in the developing world, and it is not uncommon to be faced with the grown-up patient with tetralogy physiology without previous palliation. They are more cyanotic and polycythemic and are indeed a different subset of Fallot's tetralogy from that encountered in the Western world. Although our institution is a tertiary level center, the socioeconomic profile of the patients and the lack of health insurance benefit led to delayed referral and surgery, accounting for older age of the patients. Although the study group because of late presentation selects out all the TOF variants with severe annular and/or pulmonary artery branch hypoplasia and represented the most favorable spectrum of TOF disease, the myocardium has been subjected to longstanding cyanosis and pressure overload and may account for the higher incidence of myocardial dysfunction. Using tissue Doppler interrogation, another marker of diastolic impairment, we could show diastolic dysfunction was already present preoperatively in all patients in this study, worsened significantly in all of them immediately after surgery, and remained reduced at late assessment, particularly in patients with myocardial fibrosis and greater postoperative Prv/Plv ( $\geq 0.7$ ) (Figure E7).

\section{Study Limitations}

Doppler tissue echocardiography as a technique for assessment of RV function is currently evolving as measurements continue to become validated in human populations, and normograms need to be made according to demographic variables. The Achilles heel of TDI is that it analyses one segment (sample volume) at a time, the projection of which to the entire myocardium may not be appropriate, especially when the nature of the disease is non-uniform, eg, histopathologic changes in TOF affect the RVOT more than other parts of the RV. Some indices maybe affected by loading conditions, eg, TAPSE, whereas others may have significant interobserver variability. Technical issues like poor alignment, poor windows, and a learning curve also have an impact on TDI readings.

\section{Clinical Implications and Recommendations}

The present study reflects the preponderance of degenerative changes in the myocardium of adult TOF in patients with long-standing cyanosis and pressure overload and in patients with increased right ventricular end-diastolic pressure ratio. These observations serve to emphasize the strategy of early corrective surgery before the histologic changes appear and requirement of life-long follow-up after surgical repair. Comprehensive evaluation should include a clinical, electrocardiographic, and echocardiographic evaluation with particular emphasis of the right side of the heart. Early surgical repair of these patients may prevent RV dilatation and fibrosis by decreasing the volume and pressure overload. Nevertheless, the range, prevalence, degree, and potential surgical risk posed by these abnormalities are matters that warrant emphasis.

\section{CONCLUSIONS}

Our results demonstrate the preponderance of degenerative changes in the myocardium of adult TOF in patients with long-standing cyanosis and pressure overload and may account for or may coexist with the greater incidence of myocardial dysfunction.

Among all histopathologic findings, myocytolysis and perivascular fibrosis were more prevalent among patients with high postoperative Prv/Plv. Among all TDI-derived variables, TAPSE, $s^{\prime}$, IVA, IVC, and $\mathrm{e}^{\prime}$ continued to improve in all patients. The absence of improvement of the late diastolic relaxation $\left(\mathrm{a}^{\prime}\right)$ of $\mathrm{RV}$ free wall in patients with perivascular fibrosis may be due to altered myocardial compliance and may be responsible for greater postoperative Prv/Plv. Knowledge of these histopathologic findings and their inter-relationship with TDI and postoperative Prv/Plv should contribute to the armamentarium of the cardiac surgeon for clinical management, decision-making, and prognostication of corrective surgery for TOF.

\section{Conflict of Interest Statement}

Authors have nothing to disclose with regard to commercial support.

\section{References}

1. Karamlou T, McCrindle BW, Williams WG. Surgery insight: late complications following repair of tetralogy of Fallot and related surgical strategies for management. Nat Clin Pract Cardiovasc Med. 2006;3:611-22.

2. Murphy JG, Gersh BJ, Mair DD, Fuster V, McGoon MD, Ilstrup DM, et al. Long term outcome in patients undergoing surgical repair of tetralogy of Fallot. N Eng J Med. 1993;329:593-9.

3. Chowdhury UK, Pradeep KK, Patel CD, Singh R, Kumar AS, Airan B, et al. Noninvasive assessment of repaired tetralogy of Fallot by magnetic resonance imaging and dynamic radionuclide studies. Ann Thorac Surg. 2006;81:1436-42.

4. Nollert G, Fischlein T, Bohmer C, Klinner W, Reichart B. Long term survival in patients with repair of tetralogy of Fallot: 36 year follow up of 490 survivors of the first year after surgical repair. J Am Coll Cardiol. 1997;30:1374-83.

5. Cullen S, Shore D, Redington A. Characterization of right ventricular diastolic performance after compete repair of tetralogy of Fallot: restrictive physiology predicts slow postoperative recovery. Circulation. 1995;91:1782-9.

6. Chaturvedi RR, Shore DF, Lincoln C, Mumby S, Kemp M, Brierly J, et al. Acute right ventricular restrictive physiology after repair of tetralogy of Fallot: association with myocardial injury and oxidative stress. Circulation. 1999;100:1540-7.

7. Salehian O, Burwash GI, Chan KL, Beauchesne LM. Tricuspid annular systolic velocity predicts maximal oxygen consumption during exercise in adult patients with repaired tetralogy of Fallot. J Am Soc Echocardiogr. 2008;21:342-6.

8. Puranik R, Greaves K, Hawker RE, Pressley LA, Robinson PJ, Celermajer DS Abnormal right ventricular tissue velocities after repair of congenital heart disease-implications for late outcomes. Heart Lung Circ. 2007;16:295-9. 
9. Chowdhury UK, Sathia S, Ray R, Singh R, Pradeep KK, Venugopal P. Histopathology of the right ventricular outflow tract and its relationship to clinical outcomes and arrhythmias in patients with tetralogy of Fallot. J Thorac Cardiovasc Surg. 2006;132:270-7.

10. Kouchoukos NT, Blackstone EH, Doty DB, Hanley FL, Karp RB. Anatomy dimensions, and terminology. In: Kouchoukos NT, Kirklin JW, eds. Kirklin/BarrattBoyes Cardiac Surgery. 3rd ed. Philadelphia: Churchill Livingstone; 2003:3-65.

11. Cheitlin MD, Armstrong WF, Aurigemma GP, Beller GA, Bierman FZ, Davis JL, et al. Guideline update for the clinical application of echocardiography: summary article. J Am Soc Echocardiogr. 2003;16:1091-100.

12. Rudski LG, Lai WW, Afilalo J, Hua L, Handschumacher MD, Chandrasekaran K, et al. Guidelines for the echocardiographic assessment of the right heart in adults: a report from the American Society of Echocardiography. J Am Soc Echocardiogr. 2010;23:685-713.

13. van der Hulst AE, Roest AA, Delgado V, Kroft LJ, Holman ER, Blom NA, et al. Corrected tetralogy of Fallot: comparison of tissue Doppler imaging and velocity-encoded MR for assessment of performance and temporal activation of right ventricle. Radiology. 2011;261:88-97.

14. Harada K, Toyono M, Yamamoto F. Assessment of right ventricular function during exercise with quantitative Doppler tissue imaging in children late after repair of tetralogy of Fallot. J Am Soc Echocardiogr. 2004;17:863-9.

15. Cobanoglu A, Schultz JM. Total correction on tetralogy of Fallot in the first year of life: late results. Ann Thorac Surg. 2002;74:133-8.

16. John S, Kejriwal NK, Ravi Kumar E, Bashi VV, Mohanty BB, Sukumar IP. The clinical profile and surgical treatment of tetralogy of Fallot in adults: results of repair in 200 patients. Ann Thorac Surg. 1986;41:502-6.

17. Geva T, Sandweiss BM, Gauvreau K, Lock JE, Powell AJ. Factors associated with impaired clinical status in long-term survivors of tetralogy of Fallot repair evaluated by magnetic resonance imaging. J Am Coll Cardiol. 2004;43: 1068-74.

18. Bisoi AK, Murala JSK, Airan B, Chowdhury UK, Kothari SS, Pal H, et al. Tetralogy of Fallot in teenagers and adults: surgical experience and follow-up. Gen Thorac Cardiovasc Surg. 2007;55:105-12.

19. Krymsky LD. Pathologic anatomy of congenital heart disease. Circulation. 1965; 32:814-27.

20. Deanfield JE, McKenna WJ, Presbitero P, England D, Graham GR, HallidieSmith K. Ventricular arrhythmia in unrepaired and repaired tetralogy of Fallot. Br Heart J. 1984:52:77-81.

21. Noma M, Sekiguchi A, Chikada M, Ishizawa A, Miyauchi J, Okada R. Quantitative analysis of hypertrophy in cardiac chambers in cyanotic tetralogy of Fallot. Jpn Heart J. 2001;42:173-84.
22. Hegert A, Anderson RH, Deanfield JE. Myocardial fibrosis in tetralogy of Fallot: effect of surgery or part of natural history? Br Heart J. 1996;59:123.

23. Kawai S, Okada R, Kitamura K, Suzuki A, Satio S. A morphometrical study of myocardial disarray associated with right ventricular outflow tract obstruction. Jpn Circ J. 1984;48:445-56.

24. Shan K, Bick RJ, Poindexter BJ, Shimoni S, Letsou GV, Reardon MJ, et al. Relation of tissue Doppler derived myocardial velocities to myocardial structure and beta-adrenergic receptor density in humans. J Am Coll Cardiol. 2000;36:891-6.

25. Norgard G, Gatzoulis MA, Moraes F, Lincoln C, Shore DF, Shinebourne EA, et al. Cardiovascular disease in the young: relationship between type of outflow tract repair and postoperative right ventricular diastolic physiology in tetralogy of Fallot: implications for long-term outcome. Circulation. 1996;94:3276-80.

26. Gatzoulis MA, Clark AL, Cullen S, Newman CG, Redington AN. Right ventricular diastolic function 15 to 35 years after repair of tetralogy of Fallot. Restrictive physiology predicts superior exercise performance. Circulation. 1995;91: $1775-81$.

27. Garson A, Nihill MR, McNamara DG, Cooley DA. Status of the adult and adolescent after repair of tetralogy of Fallot. Circulation. 1979;59:1232-40.

28. Rizzoli G, Mazzucco A, Fracasso A, Stellin G, Rubino M, Gallucci V. Early and late results after repair of tetralogy of Fallot. Eur J Cardiothorac Surg. 1990;4: 371-6.

29. Boni L, García E, Galletti L, Pérez A, Herrera D, Ramos V, et al. Current strategies in tetralogy of Fallot repair: pulmonary valve sparing and evolution of right ventricle/left ventricle pressures ratio. Eur J Cardiothorac Surg. 2009;35:885-90

30. Katz NM, Blackstone EH, Kirklin JW, Pacificio AD, Bargeron LM Jr. Late survival and symptoms after repair of tetralogy of Fallot. Circulation. 1982;65: 403-10.

31. Bokma JP, Winter MM, Oosterhof T, Vliegan HW, van Dijk AP, Hazekamp MG et al. Preoperative thresholds for mid-to-late haemodynamic and clinical outcomes after pulmonary valve replacement in tetralogy of Fallot. Eur Heart $J$ 2016:37:829-35.

32. Therrien J, Provost Y, Merchant N, Williams W, Colman J, Webb G. Optimal timing for pulmonary valve replacement in adults after tetralogy of Fallot repair. Am J Cardiol. 2005;95:779-82.

33. Greutmann M. Tetralogy of Fallot, pulmonary valve replacement, and right ventricular volumes: are we chasing the right target? Eur Heart J. 2016;37:836-9.

Key Words: tissue Doppler imaging, tetralogy of Fallot, myocardial histopathology, echocardiography 


\section{APPENDIX E1. DEFINITIONS \\ Echocardiographic Studies and Measurements}

These studies were performed on all patients as per the American Society of Echocardiography Criteria (HP Sonos 5500; Hewlett Packard, Andover, Mass). ${ }^{11,12}$ All patients had comprehensive evaluation with M-mode, 2-dimensional and pulsed-wave Doppler echocardiography with a respirometer recording and tissue Doppler imaging using a Philips iE33 ultrasound system (Koninklijke Philips N.V., Amsterdam, The Netherlands) with a 2.0 to $5.0 \mathrm{MHZ}$ transducer.

Pulsed tissue Doppler imaging of the right ventricle was performed from the apical 4-chamber view by placing a 5-mm sample volume at the tricuspid annulus (free wall). Peak myocardial velocities during systole $\left(\mathrm{s}^{\prime}\right)$, early diastole $\left(\mathrm{e}^{\prime}\right)$, and late diastole $\left(\mathrm{a}^{\prime}\right)$ were measured. Other systolic indices of right ventricular function (isovolumic acceleration, isovolumic contraction, and tricuspid annular plane systolic excursion) were also recorded. All measurements were performed three times and the mean value was used for analysis. These velocities were recorded for 5 consecutive cardiac cycles at a sweep speed of $100 \mathrm{~mm} / \mathrm{s}$.

Tricuspid regurgitation was assessed semiquantitatively as grade $1+$ to $4+$. Tricuspid regurgitation was considered severe if there was a jet more than $30 \mathrm{~mm}$ from the annulus or a ratio of regurgitation jet area-to-right atrial area more than $33 \%$ on Doppler echo. ${ }^{10}$

Pulmonary regurgitation was assessed from both continuous-wave Doppler trace and color-flow mapping. Pulmonary regurgitation was classified as mild when the retrograde pressure drop was maintained throughout diastole, moderate when equilibration between pulmonary artery and right ventricular pressures occurred in late diastole, and severe when it met the baseline in middiastole or earlier. ${ }^{10}$ Persistent (residual) pulmonary valvular stenosis was considered present when the peak systolic right ventricular outflow tract gradient was $\geq 30 \mathrm{~mm} \mathrm{Hg} .{ }^{10}$

Tricuspid Annular Plane Systolic Excursion, cm. Also known as tricuspid annular motion, it is simplest to obtain and the most widely studied Doppler tissue echocardiographic variable as a marker of right ventricular function in systole. From an apical 4-chamber view, it measures the longitudinal systolic apical descent of the tricuspid valve annulus (taken along right ventricular free wall) with the obvious surmise that the greater the descent, the better the right ventricular function. It has been shown to correlate well with radio nucleotide studies and has low intraobserver variability. ${ }^{13,14}$ However, it lacks extensive validation studies and it maybe preload dependent. Lower reference value for impaired right ventricular function is taken as $16 \mathrm{~mm} .{ }^{10}$

$\mathbf{e}^{\prime}, \mathbf{c m} / \mathbf{s}$. It denotes diastolic basal wall lengthening of right ventricle in early diastole, representing the early passive filling of the right ventricle. ${ }^{11,12}$ $\mathbf{a}^{\prime}, \mathbf{c m} / \mathbf{s}$. It denotes diastolic basal wall lengthening of right ventricle in late diastole, representing atrial contraction, ie, the active filling. ${ }^{11,12}$

Isovolumic contraction, $\mathbf{c m} / \mathbf{s}$. It is the shortening of basal right ventricular wall during isovolumic ventricular contraction. ${ }^{11,12}$

Isovolumic acceleration, $\mathbf{c m} / \mathbf{s}^{\mathbf{2}}$. Isovolumic acceleration is the acceleration of basal right ventricular wall during isovolumic ventricular contraction. It is apparently less dependent on loading conditions than other ejection period indices. ${ }^{11,12}$ It varies with heart rate and is age dependent. Lower reference values are suggested as $2.2 \mathrm{~m} / \mathrm{s}^{2}$.

$\mathbf{s}^{\prime}, \mathbf{c m} / \mathbf{s}$. It denotes peak myocardial velocity during systole. It correlates directly with right ventricular force of contraction. It is measured via an apical 4-chambered view with pulsed Doppler volume placed on lateral tricuspid annulus. It has been shown to be an independent predictor of exercise capacity in operated patients of tetralogy of Fallot. ${ }^{13}$ Although its use has been validated in population-based studies, it is less reproducible and values less than $10 \mathrm{~cm} / \mathrm{s}$ suggest right ventricular dysfunction, especially in a young adult. ${ }^{10-12}$

\section{Light Microscopic Evaluation}

For light microscopy, the specimens were fixed in $10 \%$ neutral buffered formalin at room temperature. The tissues were subjected to conventional paraffin processing. Sections 4 to $5 \mu \mathrm{m}$ thick were cut and were stained by hematoxylin and eosin. Special staining using Masson's trichrome and elastic van Gieson was performed when required. Serial sections were examined with a research light microscope (model B-50; Olympus Corp, Tokyo, Japan; magnification $80 \times$ or $160 \times)$.

\section{Low Cardiac Output Syndrome}

Low cardiac output syndrome in patients with repaired tetralogy of Fallot was diagnosed if the patient required inotropic support (dopamine at 4-10 $\mu \mathrm{g} /[\mathrm{kg} \cdot \mathrm{min}]$ ), dobutamine at 5 to $10 \mu \mathrm{g} /[\mathrm{kg} \cdot \mathrm{min}]$, and epinephrine at 0.01 to $0.1 \mu \mathrm{g} /[\mathrm{kg} \cdot \mathrm{min}]$ either isolated or in combination in the operating room or in the intensive care unit, to maintain stable hemodynamics in the absence of residual structural lesions and mechanical external compression after correction of all electrolytes or blood gas abnormalities and after adjustment of the preload to its optimal value. Low-output syndrome was also diagnosed if there was an increasing requirement of the aforementioned inotropes with or without intra-aortic balloon counterpulsation along with afterload reduction with sodium nitroprusside. Patients who received less than $4 \mu \mathrm{g} /(\mathrm{kg} \cdot \mathrm{min})$ dopamine to increase renal perfusion were not considered to have low output syndrome. ${ }^{9}$ 

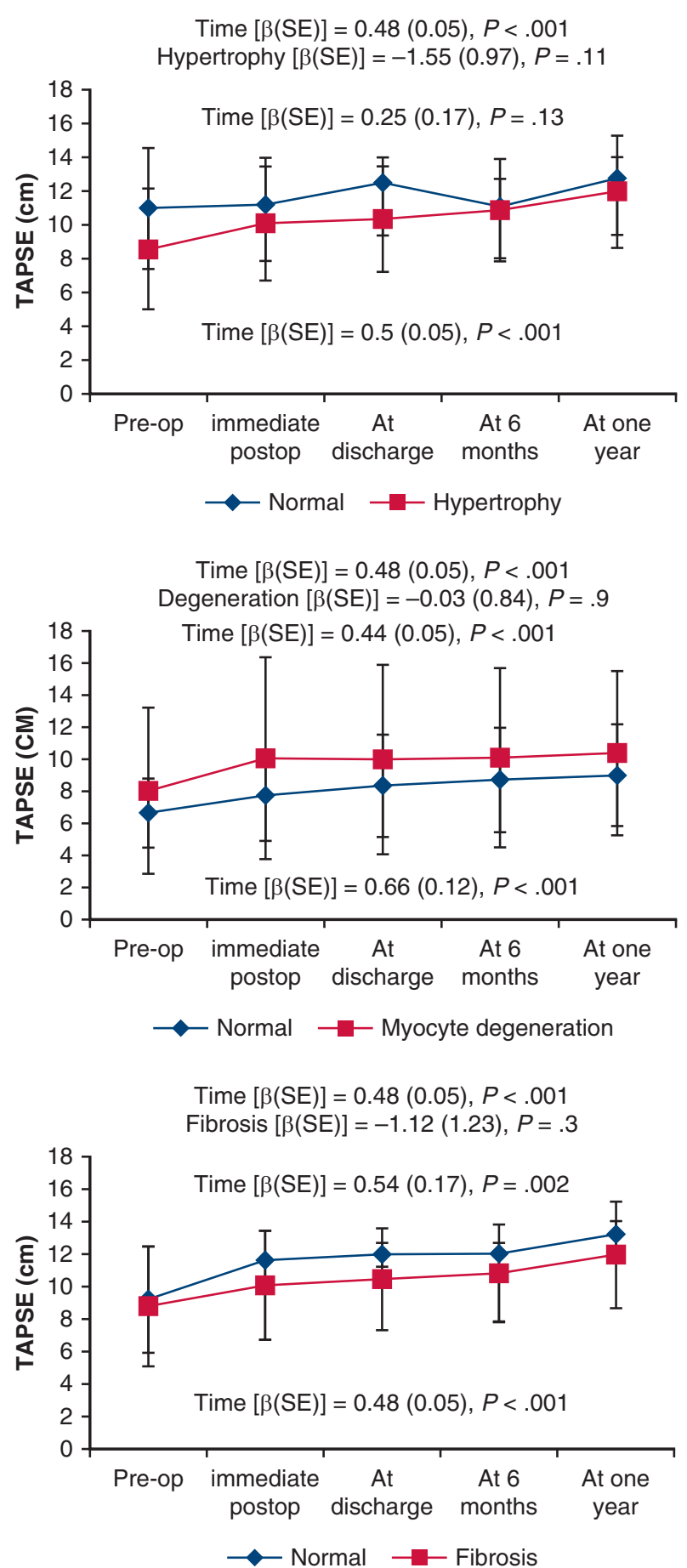

FIGURE E1. Graphical representation of the progression of tricuspid annular plane systolic excursion (TAPSE) during follow-up in patients undergoing intracardiac repair of tetralogy of Fallot with normal and abnormal histology in the study group $(n=93)$. Postoperatively, there was a significant improvement in TAPSE values in all patients with normal histology as compared with abnormal histology (myocardial hypertrophy, myocyte degeneration, perivascular fibrosis) during follow-up. $\beta$, Regression coefficient; $S E$, standard error.

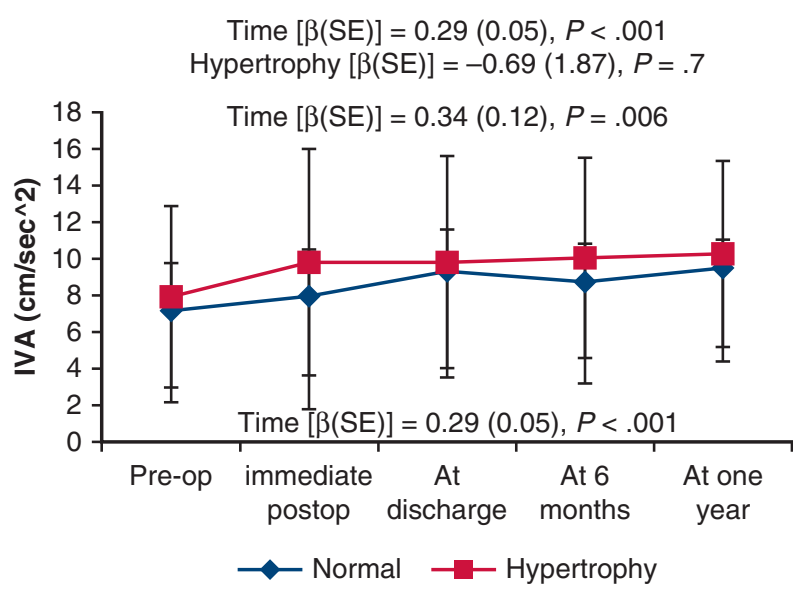

Time $[\beta(\mathrm{SE})]=0.29(0.05), P<.001$ Degeneration $[\beta(\mathrm{SE})]=-1.68(1.57), P=.28$

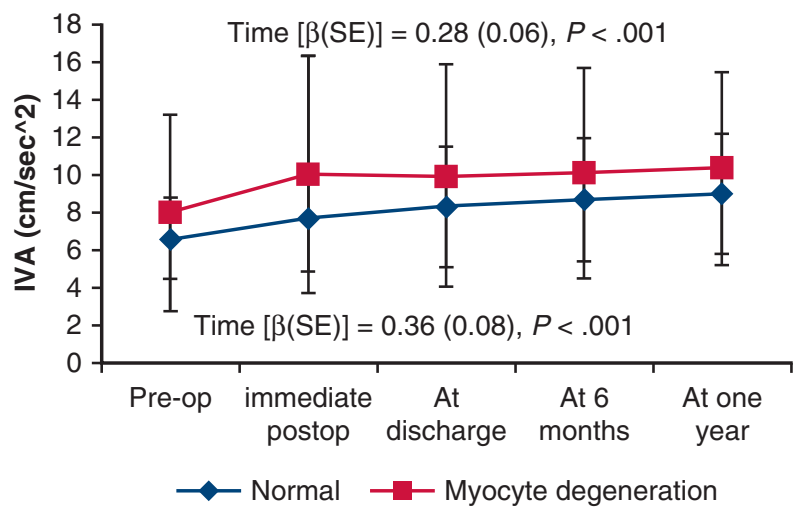

Time $[\beta(\mathrm{SE})]=0.29(0.05), P<.001$

Fibrosis $[\beta(\mathrm{SE})]=-0.49(1.03), P=.63$

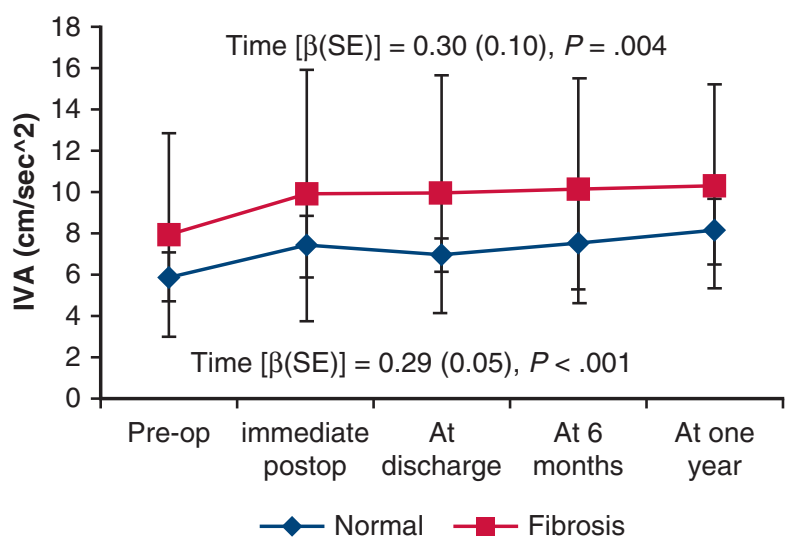

FIGURE E2. Graphical representation of the progression of isovolumic acceleration (IVA) during follow-up in patients undergoing intracardiac repair of tetralogy of Fallot with normal and abnormal histology in the study group $(n=93)$. Postoperatively, there was a significant improvement in IVA values in all patients with normal histology as compared with abnormal histology (myocardial hypertrophy, myocyte degeneration, perivascular fibrosis) during follow-up. $\beta$, Regression coefficient; $S E$, standard error. 
Time $[\beta(\mathrm{SE})]=0.31(0.04), P<.001$

Hypertrophy $[\beta(\mathrm{SE})]=-1.36(0.91), P=.13$

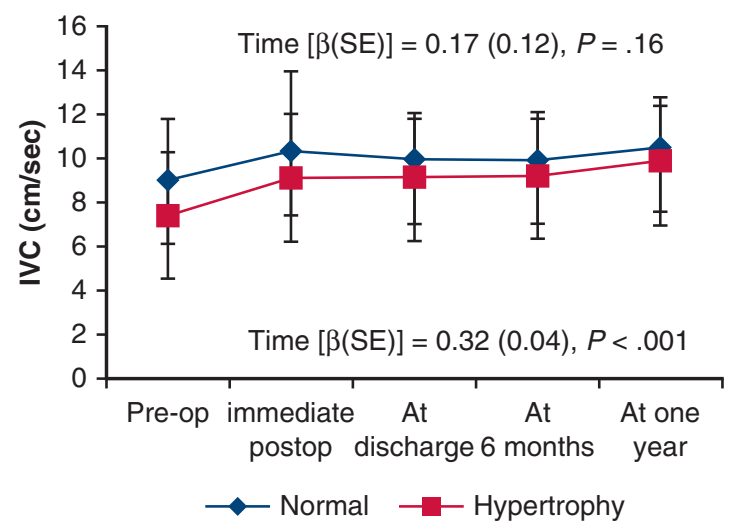

Time $[\beta(\mathrm{SE})]=0.31(0.04), P<.001$ Degeneration $[\beta(\mathrm{SE})]=0.06(0.79), P=.9$

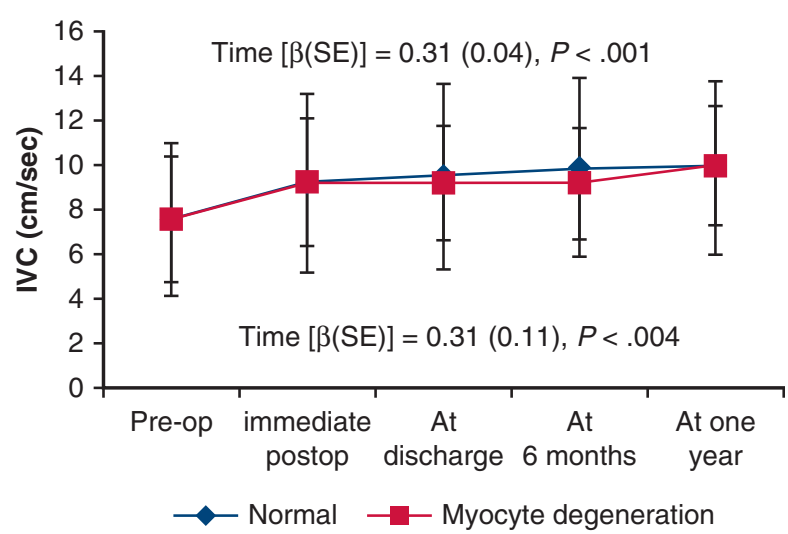

Time $[\beta(\mathrm{SE})]=0.31(0.04), P<.001$

Fibrosis $[\beta(\mathrm{SE})]=-0.82(1.15), P=.4$

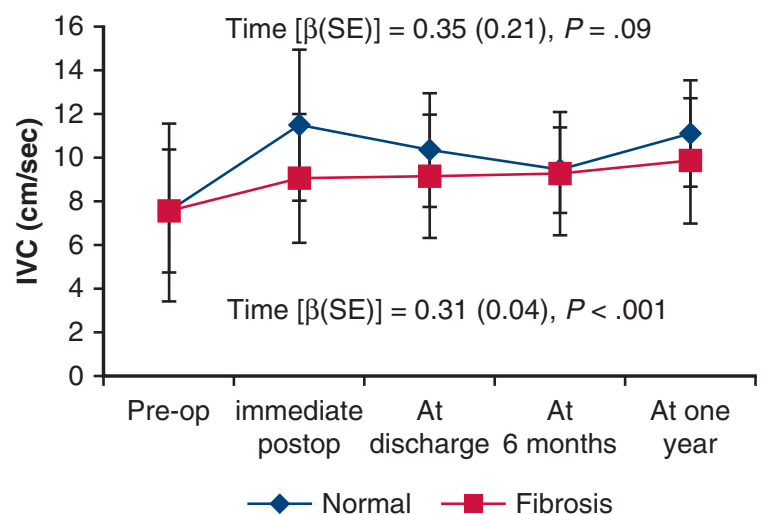

FIGURE E3. Graphical representation of the progression of isovolumic contraction $(I V C)$ during follow-up in patients undergoing intracardiac repair of tetralogy of Fallot with normal and abnormal histology in the study group $(\mathrm{n}=93)$. Postoperatively, there was a significant improvement in IVC values in all patients with normal histology as compared with abnormal histology (myocardial hypertrophy, myocyte degeneration, perivascular fibrosis) during follow-up. $\beta$, Regression coefficient; $S E$, standard error.

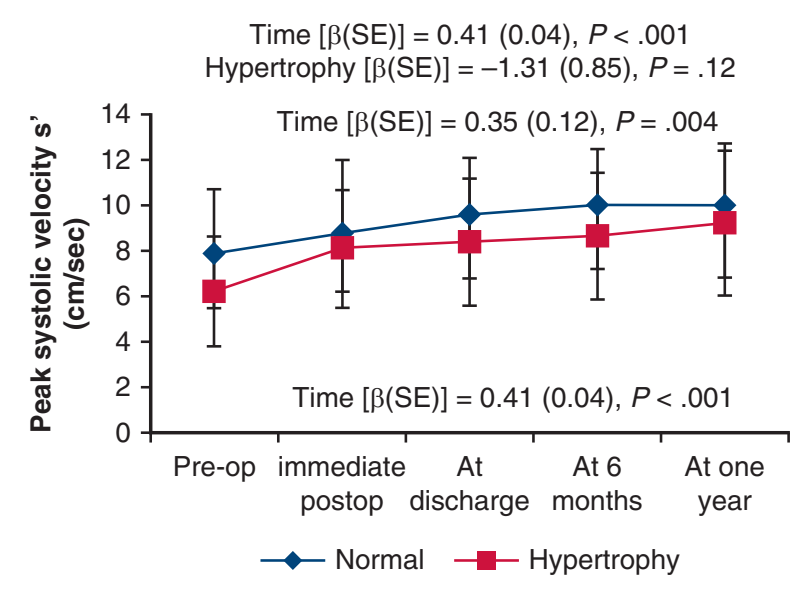

Time $[\beta(\mathrm{SE})]=0.41(0.04), P<.001$ Degeneration $[\beta(\mathrm{SE})]=0.46(0.73), P=.5$

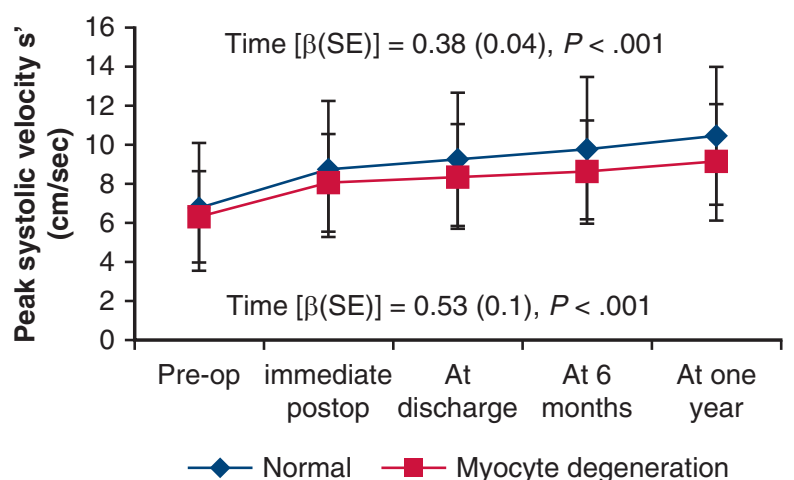

Time $[\beta(\mathrm{SE})]=0.41(0.04), P<.001$

Fibrosis $[\beta(\mathrm{SE})]=-1.24(1.06), P=.2$

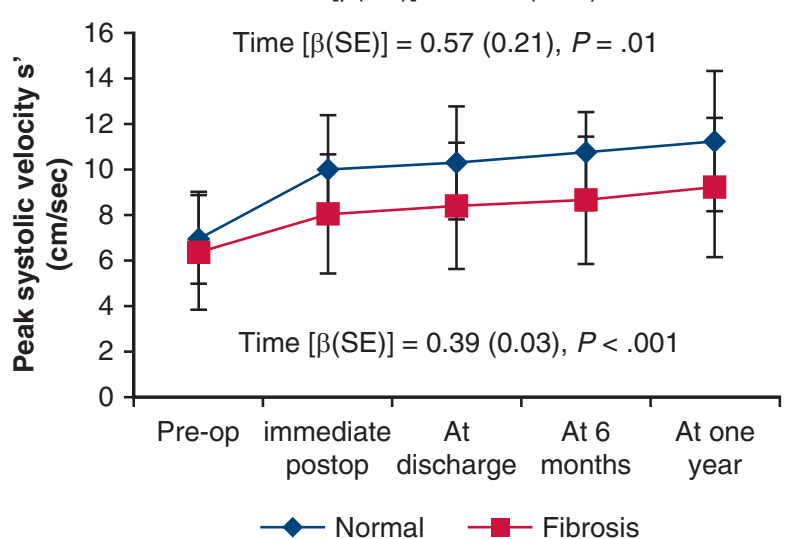

FIGURE E4. Graphical representation of the progression of peak myocardial velocity during systole $\left(\mathrm{s}^{\prime}\right)$ during follow-up in patients undergoing intracardiac repair of tetralogy of Fallot with normal and abnormal histology in the study group $(\mathrm{n}=93)$. Postoperatively, there was a significant improvement in $\mathrm{s}^{\prime}$ values in all patients with normal histology as compared with abnormal histology (myocardial hypertrophy, myocyte degeneration, perivascular fibrosis) during follow-up. $\beta$, Regression coefficient; $S E$, standard error. 


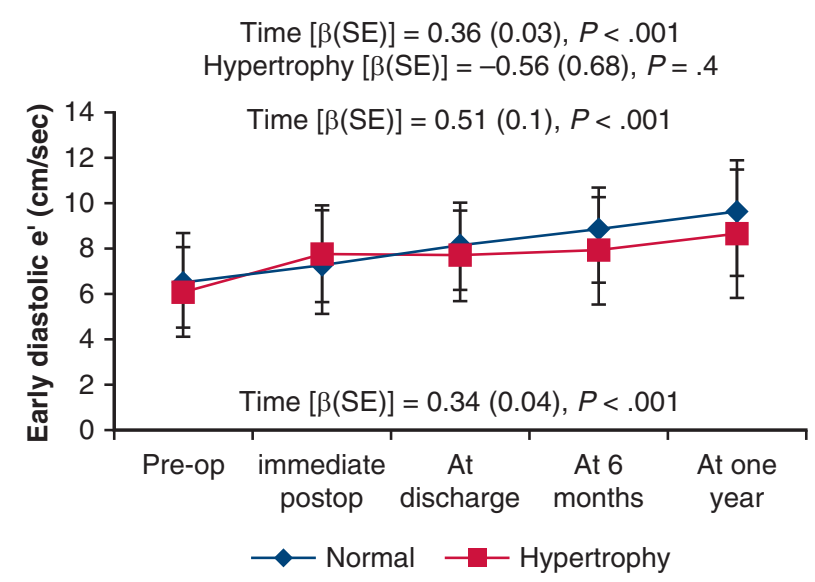

Time $[\beta(\mathrm{SE})]=0.36(0.04), P<.001$ Degeneration $[\beta(\mathrm{SE})]=0.42(0.58), P=.4$

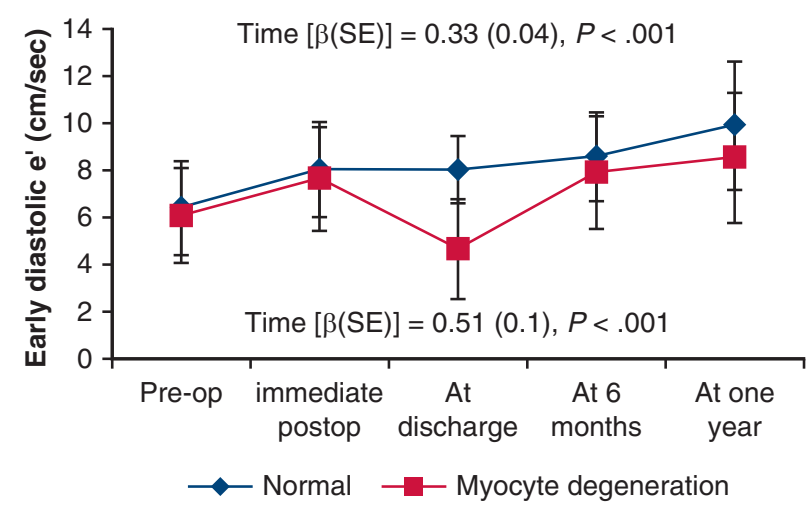

Time $[\beta(\mathrm{SE})]=0.36(0.03), P<.001$

Fibrosis $[\beta(\mathrm{SE})]=-1.52(0.83), P=.06$

$$
\left.{ }^{16}\right] \quad \text { Time }[\beta(\mathrm{SE})]=0.66(0.13), P<.001
$$

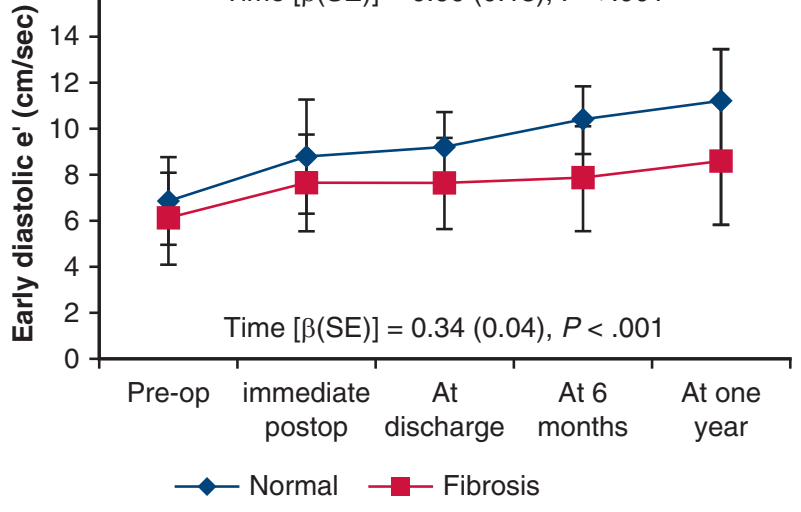

FIGURE E5. Graphical representation of the progression of diastolic basal wall lengthening of right ventricle in early diastole ( $\left.\mathrm{e}^{\prime}\right)$ during follow-up in patients undergoing intracardiac repair of tetralogy of Fallot with normal and abnormal histology in the study group $(\mathrm{n}=93)$. Postoperatively, there was a significant improvement in $\mathrm{e}^{\prime}$ values in all patients with normal histology as compared with abnormal histology (myocardial hypertrophy, myocyte degeneration, perivascular fibrosis) during followup. $\beta$, Regression coefficient; $S E$, standard error.
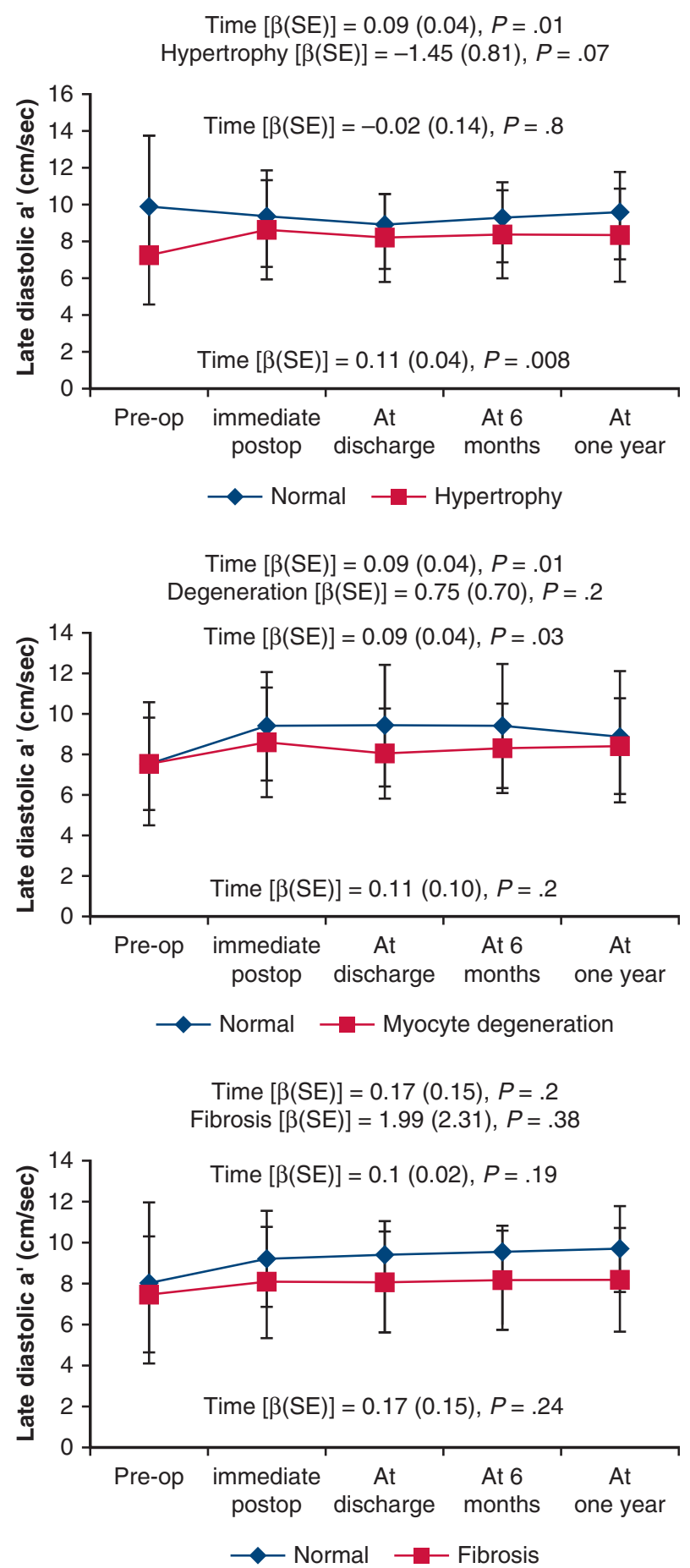

FIGURE E6. Graphical representation of the progression of diastolic basal wall lengthening of right ventricle in late diastole $\left(a^{\prime}\right)$ during follow-up in patients undergoing intracardiac repair of tetralogy of Fallot with normal and abnormal histology in the study group $(n=93)$. Postoperatively, although was a significant improvement in $\mathrm{a}^{\prime}$ values in all patients with myocardial hypertrophy and myocardial degeneration as compared with normal histology, there was no improvement in diastolic basal wall lengthening in late diastole $\left(\mathrm{a}^{\prime}\right)$ during follow-up in patients with myocardial fibrosis. $\beta$, Regression coefficient; $S E$, standard error. 


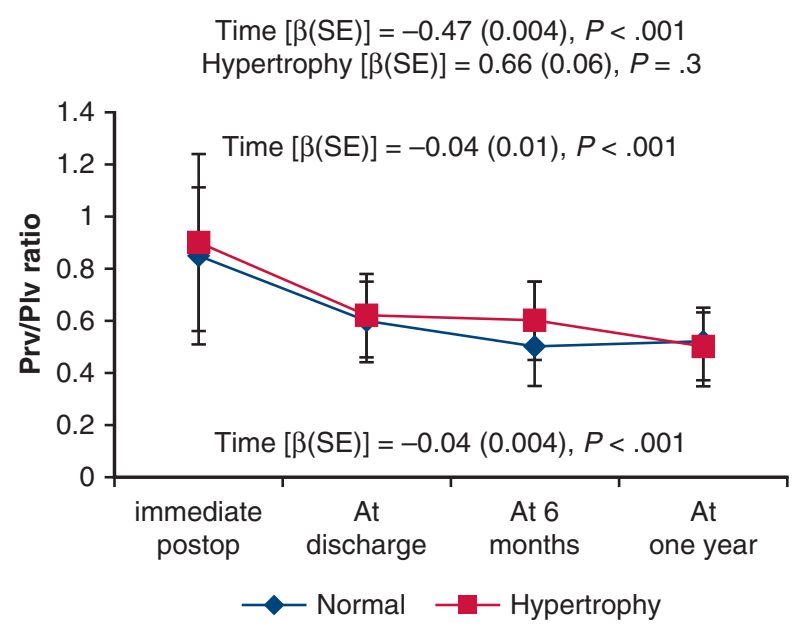

Time $[\beta(\mathrm{SE})]=-0.04(0.004), P<.001$

Degeneration $[\beta(\mathrm{SE})]=0.08(0.05), P=.1$

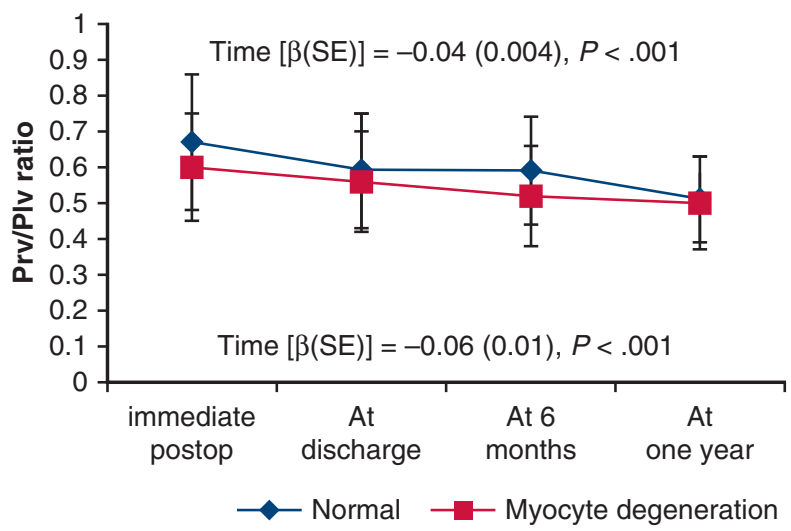

Time $[\beta(\mathrm{SE})]=-0.47(0.004), P<.001$

Fibrosis $[\beta(\mathrm{SE})]=-0.07(0.08), P=.3$

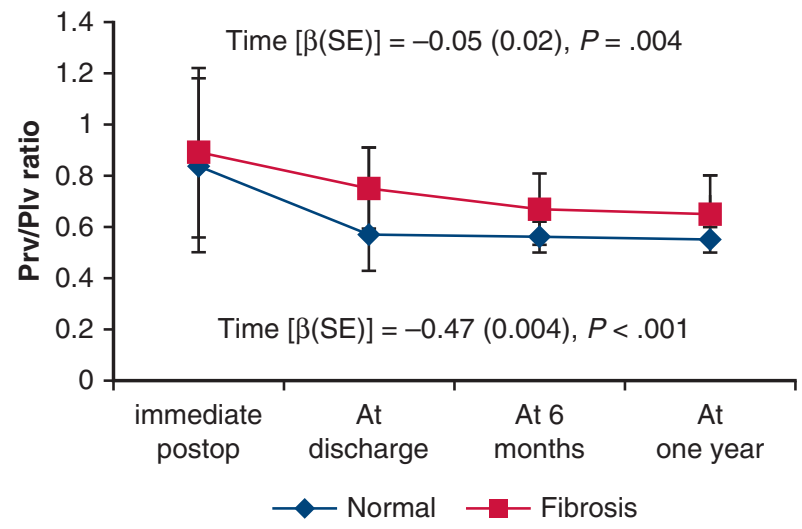

FIGURE E7. Graphical representation of evolution of postoperative peak systolic right-to-left ventricular pressure ratio $(\mathrm{Prv} / \mathrm{Plv})$ during follow-up in patients undergoing intracardiac repair of tetralogy of Fallot with normal and abnormal histology (myocardial hypertrophy, myocyte degeneration, perivascular fibrosis) in the study group $(n=93)$. Although there was improvement of postoperative Prv/Plv in patients with myocardial fibrosis as compared with normal histology, the values were not statistically significant $(\beta=-0.07$, standard error $=0.08, P=.3)$. $\beta$, Regression coefficient; $S E$, standard error. 